\title{
Differential Performance of Individual and Consortial Endophytes for Enhanced Rice Yield and Agronomic N-Use Efficiency in Open-Fields in the Nile Delta
}

\author{
Youssef G Yanni* ${ }^{1 *}$, Frank B Dazzo ${ }^{2}$ and Abdelgawad Y Elsadany ${ }^{1}$ \\ ${ }^{1}$ Professor of Microbiology, Department of Microbiology, Sakha Agricultural Research Station, Sakha, Kafr Elsheikh, Egypt \\ ${ }^{2}$ Professor of Microbiology, Department of Microbiology and Molecular Genetics, Michigan State University, East Lansing, USA \\ ${ }^{3}$ Researcher, Department of Microbiology, Sakha Agricultural Research Station, Sakha, Kafr Elsheikh, Egypt \\ *Corresponding Author: Youssef G Yanni, Professor of Microbiology, Soils, Water and Environment Research Institute - Agricultural \\ Research Center, Giza. Sakha Agricultural Research Station, Kafr Elsheikh, Egypt.
}

Orcid ID: https://orcid.org/0000-0002-7461-7551

Research Gate: https://www.researchgate.net/profile/Youssef_Yanni2

Received: June 24, 2019; Published: July 15, 2019

DOI: $10.31080 /$ ASMI.2019.02.0310

\begin{abstract}
Under real-world agricultural field conditions, environmental friendly biofertilizers were explored to reduce excessive N-fertilizer applications for production of high rice paddy yields. Strains of clover-nodulating Rhizobium leguminosarum bv. trifolii, Pseudomonas stutzeri and Nostoc sp. were isolated from surface-sterilized roots of rice (Oryza sativa) grown in the Nile Delta, identified by $16 \mathrm{~S}$ rDNA sequence analysis and used individually or as consortia for rice field inoculation, firstly in gnotobiotic lab tests followed by 14 translational open field tests at 30o 44'50" to 31015'38' N and 30o 37'32" to 31o 12'19" E in the Nile delta. Six different rice cultivars and $3 \mathrm{~N}$ fertilization rates were implemented. The strains expressed high potential as enhancers of rice growth, yield and agronomic fertilizer N-use efficiency. Inoculation increased grain yields by 18.9 - 22.4\% compared to yields in adjacent uninoculated farmer's fields, and by $18.9-32.7,20.2$ - 33.0 and $22.4-31.2 \%$ increases in fertilizer N-use efficiencies using individual, double or triple strain consortia inoculation, respectively, even with the full recommended $\mathrm{N}$ fertilizer dose for the 6 rice cultivars. Individual, double or triple strain consortia significantly enhanced yield and fertilizer N-use at 7, 4 and 3 of the 14 experimental locations, respectively. Biofertilization could not fully replace the need to apply N-fertilizers to achieve maximal rice production under the prevailing agroecological conditions. This study documents the benefit of biofertilizer inoculation to enhance agricultural sustainability, environmental soundness and economic farming managements for better rice production from the same but non-biofertilized rice fields.
\end{abstract}

Keywords: Bacterial consortia; Biofertilization; Endophytes; Nostoc; N-use Efficiency; Pseudomonas; Rhizobium; Rice

\section{Introduction}

Billions of tons of synthetic fertilizers are currently used to enhance legume and cereal production despite the recognition that many beneficial plant/microbe associations are environmental friendly, safe and sound alternatives. Currently, cereal production requires major $\mathrm{N}$ inputs to achieve global food security, although they can utilize basal levels of fixed-N from biological $\mathrm{N}_{2}$-fixation (BNF) by diverse diazotrophs in their agro-ecosystems. Worldwide attempts have been made to solve that challenge by integrating lab studies, greenhouse tests and translational field experiments followed by technology transfer programs to apply biofertilizer technologies as a cornerstone in crop fertilization. The results indicated that catastrophic economic and environmental problems due to excessive chemical fertilizer applications could be mitigated if cereals could establish more direct associations with beneficial bacteria that promote their growth and increase yield with less dependence on chemical $\mathrm{N}$-fertilizer inputs, being ecofriendly, environmentally safe and consistent with agriculture sustainability. The potential added benefits of biofertilizers containing multi-strain consortia for crop production has begun to be explored [1-6], including the 
adoption of several undefined consortia based on their ability to express N2-fixing activity and produce bioactive indolic compounds [7]. They concluded that continuous enrichment of undefined consortia from sampled root/rhizosphere soil in an $\mathrm{N}$-free medium is a good strategy to select rice growth-promoting bacteria. Although extensive performance tests of multi-strain consortial inoculants under real-world agronomic conditions in large-scale farmers' fields is very important, such studies are currently limited, requiring further examination to fully assess their potential and efficiently implement the biofertilizer technology. This lack of sufficient, extensive, experimentally proven effectiveness of biofertilizers containing multi-strain consortia at multiple locations differing in edaphic characteristics provided the motivation to fill this gap.

One aim of this study was to isolate and identify ecofriendly microbial biofertilizer candidates from field-grown surface-sterilized rice roots, and the other was to assess whether the performance of the rice biofertilizer would be improved if formulated to contain a verified biofertilizer strain of rhizobia that was combined in consortia with other optimized microbial candidates rather than be used alone. This second aim was to target comprehensive assessment of the performance of biofertilizer formulations prepared using single strains and consortia to enhance productivity and the agronomic fertilizer $\mathrm{N}$-use efficiency of some important rice varieties when implemented under the agronomic conditions of intensive rice farming conditions that prevail in the Egypt Nile delta. The study was extensive, performed in large-scale inoculation experiments using 3 main-plot treatments of $\mathrm{N}$-fertilization and 7 sub-plot treatments of inoculation with single effective biofertilizer strains and their consortia, and conducted in 14 farmers' fields at seven locations belonging to two governorates within the Nile delta.

\section{Materials and Methods}

Lab tests

Isolation of rice endophytes

The Rhizobium leguminosarum bv. trifolii strain E11 used in this study was previously isolated from within surface-sterilized roots of field-grown rice near the Sakha Agricultural Research Station, Kafr El-Sheikh, Egypt [8,9]. It formed root nodules and effectively fixed $\mathrm{N}_{2}$ on its natural legume host, berseem clover (Trifolium alexandrinum), and expressed no negative or contradictory effects on rice that alternates with the clover in the same crop rotation. The isolate has performed well as a single-strain biofertilizer that increased rice vegetative growth, agronomic fertilizer N-use efficiency, straw production and grain yields in extensive inoculation tests conducted in the laboratory, greenhouse, small experimental field plots, and in large scaled-up farmers' fields in the Egypt Nile delta [8-10].

As for isolation of other biofertilizer strains, roots of field-grown rice (Giza 178) were collected from cultivated areas in Sakha. The roots were washed with running tap water, blotted dry, surface-sterilized with $70 \%$ ethanol for $3 \mathrm{~min}$. followed by $10 \%$ sodium hypochlorite solution for $2 \mathrm{~min}$. To verify the surface-sterilization process, treated root samples were rolled over agar plates containing the malate $\mathrm{N}$-free medium [11] formulated for isolation of azospirilla, and on agar medium [12] for cyanobacteria. The malate $\mathrm{N}$-free plates were incubated at $32^{\circ} \mathrm{C}$ for 8 days, while the plates for cyanobacteria were incubated in an illuminated lab greenhouse for 10 days. The remaining surface-sterilized roots were stored aseptically at $6^{\circ} \mathrm{C}$. The stored roots were macerated in sterile $5 \mathrm{mM}$ Na-phosphate buffer ( $\mathrm{pH} 7.0$ ), then inoculated into tube deeps of semisolid malate $\mathrm{N}$-free medium [11]. After incubation for 8 days at $32^{\circ} \mathrm{C}$, inocula from positive tubes showing subsurface microaerophilic growth characteristic for Azospirillum were streaked on plates containing the same malate $\mathrm{N}$-free medium solidified with purified agar (16 g/liter), and then incubated further for 8 days. Colonies resembling previously described characteristics for Azospirillum [11] were selected, re-streaked, incubated and transferred to stock cultures of the same medium. For isolation of cyanobacteria, individual colonies that developed on the corresponding $\mathrm{N}$-free agar medium [12] inoculated with macerates of surface-sterilized roots were re-streaked several times followed by microscopic examinations of isolated colonies to further validate their pure culture status. Strong flourishing colonial growth of cyanobacterial isolates on the N-free agar medium provided evidence of their potential to fix atmospheric N2. Possible production of cyanobacterial hepatotoxic microcystins was examined by the ELISA assay [13].

\section{Strains identification}

The taxonomic affiliations of the isolates were explored by sequence analysis of segments of their PCR-amplified $16 \mathrm{~S}$ rRNA-encoding gene using the primer 8F performed in the Genomics Core Support Facility at Michigan State University, USA, followed by a sequence similarity analysis using the online SeqMatch tool of the Ribosomal Database Project (https://rdp.cme.msu.edu/seqmatch/seqmatch_intro.jsp (Accessed 20 June 2019)). 
Differential Performance of Individual and Consortial Endophytes for Enhanced Rice Yield and Agronomic N-Use Efficiency in Open-Fields in the Nile Delta

\section{Assessment of rice growth promotion capabilities}

Individual or consortia combinations of the isolated strains were tested in enclosed tubes under gnotobiotic conditions in growth chambers for growth promotion of the Egyptian rice cvs Giza 177, Giza 178, Sakha 101 and Sakha 104, commonly used by rice producers in the Nile delta. The rhizobial inoculum was grown on defined BIII agar medium [14] for 5 days at $30^{\circ} \mathrm{C}$, and then suspended in sterile Hoagland's solution to a density of $10^{7} \mathrm{CFU}$ (Colony-Forming Units)/ml. The cyanobacterial inoculum was grown on the $\mathrm{N}$-free modified Watanabe medium [12] for 10 days at $30^{\circ} \mathrm{C}$ with a $14 \mathrm{hrs}$./day photoperiod. The Pseudomonas isolate was cultivated on agar plates of the malate $\mathrm{N}$-free medium of [11] for 8 days at $32^{\circ} \mathrm{C}$. Rice seeds weighing approximately $150 \mathrm{mg}$ each were surface-sterilized by a 1-min treatment with $70 \%$ ethanol followed by 4 min with $10 \%$ sodium hypochlorite solution, then washed several times with sterile distilled water under aseptic conditions. Separate cultivation tests proved that the surface of the seeds harbored no culturable bacteria. The seeds were then transferred to glass tubes $(200 \mathrm{~mm}$ in length, $25 \mathrm{~mm}$ internal diameter, sealed with foam plugs), each containing $20 \mathrm{ml}$ of sterile half-strength Hoagland's \#2 solution (Sigma Chem. Co., St. Louis, M0), solidified with 1\% Difco purified agar (United States Biochemical, Cleveland, $\mathrm{OH}$ ). The tubes were incubated for 2 days in the dark at $30^{\circ} \mathrm{C}$ for seed germination. Each seedling root was inoculated with $10^{6} \mathrm{CFU}$ of each isolate strain independently or together as a consortium. The test included non-inoculated control seedlings and six replicates for each cultivar/inoculant treatment.

The plants were uprooted after 32 days. Shoot biomass (stem plus leaves) was oven-dried at $70^{\circ} \mathrm{C}$ for 3 days followed by $4 \mathrm{hrs}$. at $105^{\circ} \mathrm{C}$ and then weighed. The plants were digitally scanned and the images were used to estimate the cumulative length of roots and rootlets, biovolume and surface area using the CMEIAS software [Center for Microbial Ecology Image Analysis System (http://cme. msu.edu/cmeias/. Accessed 20 June 2019)] [15,16]. The collected data were used as indicators of rice growth-promotion capabilities of the test individual or consortia strain inoculants.

\section{Field tests}

\section{Primary information}

We conducted 14 translational inoculation experiments in rice production fields (authorized by the research team and local farmers) in the Algharbia and Kafr El-Sheikh governorates $\left(30^{\circ}\right.$ $44^{\prime} 50^{\prime \prime}-31^{\circ} 15^{\prime} 38^{\prime \prime} \mathrm{N}$ and $\left.30 \mathrm{o} 38^{\prime} 46^{\prime \prime}-31^{\circ} 12^{\prime} 19^{\prime \prime} \mathrm{E}\right)$ at the central and north regions of the Nile delta, respectively (Figure 1). Table 1 presents each numbered experiment, the governorate and nearest cities to the field, growing season, previous crops, rice cv and the Cartesian coordinates of the test field location. The field soils originated from sediments deposited over thousands of annual Nile flood seasons. Characteristics of corresponding $0 / 30 \mathrm{~cm}$ topsoil samples included electrical conductivities of $1.78-2.18 \mathrm{dSm}^{-1}$, sodium adsorption ratio of $2.34-4.18$, soluble cations and anions (meq/l): $\mathrm{K}^{+} 0.05-0.29, \mathrm{Na}^{+} 3.89-10.01, \mathrm{Mg}^{2+} 3.18-4.95, \mathrm{Ca}^{2+} 6.8$ $-10.05, \mathrm{CO}_{3}{ }^{2-} 0.05-0.52, \mathrm{HCO}_{3-} 5.00-9.14, \mathrm{Cl}-7.00-16.00, \mathrm{SO}_{4}{ }^{2}-$ 3.55 - 6.36, exchangeable sodium percentage of $6.18-10.36$, cation exchange capacities of 45.2 - $58.5 \mathrm{meq} / 100 \mathrm{~g}$, available $\mathrm{N}, \mathrm{P}, \mathrm{K}$ of $35-61,8-13,476-831 \mathrm{ppm}$, respectively, hygroscopic water content of $4.9-7.5 \%$, and water saturation percentages of $75.9-$ $97.1 \mathrm{ml}$ water/100 g soil. Soil mechanical analyses revealed clay, clay-loam, silty-clay and silty-clay-loam textures with $35.2-45.1 \%$ clay, $33.1-39.2 \%$ silt and $21.8-36.7 \%$ sand. All field soils had low organic matter contents of $1.93-2.74 \%$, which typically accompanies high soil temperatures and slightly alkaline $\mathrm{pH}$ values of 7.9 to 8.3 that are favorable for accelerated organic matter decomposition. The soils contained 1.86 to $3.42 \%$ active $\mathrm{CaCO}_{3}$, inducing high potentials of $\mathrm{P}$ fixation into non-soluble/unavailable $\mathrm{Ca}_{3}\left(\mathrm{PO}_{4}\right)_{2}$.
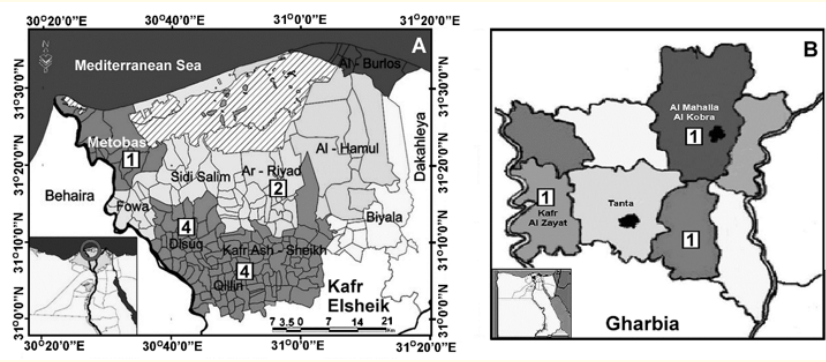

Figure 1: A and B Number and location(s) of experimental field test sites in various counties within the Nile Delta. A) 11 experiments in 4 counties within the Kafr El-Sheikh governorate. B) 3 experiments in 3 counties within the Gharbia governorate. More details are provided in Table 1.

The rice cultivars used were: Giza 177, Sakha 101,102, 103, 104 and 105. Dried rice seeds were soaked in cloth bags for 1-2 days and allowed to germinate for another 1-2 days (depending on the rice cultivar). The emerged seedlings were uniformly broadcasted 
Differential Performance of Individual and Consortial Endophytes for Enhanced Rice Yield and Agronomic N-Use Efficiency in Open-Fields in the Nile Delta

on levee-enclosed nursery areas covered with water to a head of $3 \mathrm{~cm}$. The herbicide "Saturn 50\%" [Benzthiocarb: S-(4-chlorobenzyl)-N, N diethylthiocarbamate] was applied at $4.8 \mathrm{~L} /$ ha four days later. Seedlings in the nurseries were grown for 28 - 31 days following their broadcast. The seedlings were then gently uprooted from the nursery and transplanted manually in groups of 2 to 3 seedlings at corners of $20 \times 20 \mathrm{~cm}$ squares, resulting in a field stand density of 250,000 seedling group/ha.

Table 1: Location, sub-plot area*, previous crop, rice cv and the Cartesian coordinates for each experimentation location.

\begin{tabular}{|c|c|c|c|c|}
\hline Expt & $\begin{array}{l}\text { Governorate } \\
\text { (Nearest central city-location) }\end{array}$ & $\begin{array}{l}\text { Previous } \\
\text { crop }\end{array}$ & Rice cv & $\begin{array}{l}\text { Latitude-Longitude coordinates } \\
\text { for experimental location }\end{array}$ \\
\hline \multicolumn{5}{|c|}{ Season 2009} \\
\hline 1 & KF (Alread-Kobri Alzawia) & wheat & Sakha102 & $31^{\circ} 15^{\prime} 38^{\prime \prime} \mathrm{N}$ and $31^{\circ} 2^{\prime} 8^{\prime \prime} \mathrm{E}$ \\
\hline 2 & KF (Qalien-Alkordy) & wheat & Giza177 & $31^{\circ} 4^{\prime} 34^{\prime \prime} \mathrm{N}$ and $30^{\circ} 49^{\prime} 5^{\prime \prime} \mathrm{E}$ \\
\hline 3 & KF (Qalien-Alkordy) & wheat & Giza177 & $31^{\circ} 4^{\prime} 32^{\prime \prime} \mathrm{N}$ and $30^{\circ} 49^{\prime} 5^{\prime \prime} \mathrm{E}$ \\
\hline 4 & KF (Qalein-Shabas Emeir) & wheat & Giza177 & $31^{\circ} 5^{\prime} 48^{\prime \prime} \mathrm{N}$ and $30^{\circ} 47^{\prime} 33^{\prime \prime} \mathrm{E}$ \\
\hline 5 & KF (Dessouk-Alkaradwa) & wheat & Sakha103 & $31^{\circ} 7^{\prime} 42^{\prime \prime} \mathrm{N}$ and $30^{\circ} 38^{\prime} 46^{\prime \prime} \mathrm{E}$ \\
\hline 6 & KF (Dessouk-Algamalya) & wheat & Sakha103 & $31^{\circ} 7^{\prime} 42^{\prime \prime} \mathrm{N}$ and $30^{\circ} 38^{\prime} 46^{\prime \prime} \mathrm{E}$ \\
\hline 7 & GH (Alsanta-Tatia) & wheat & Sakha101 & $30^{\circ} 44^{\prime} 50^{\prime \prime} \mathrm{N}$ and $31^{\circ} 7^{\prime} 49^{\prime \prime} \mathrm{E}$ \\
\hline 8 & GH (Almahala Alkobra-Alkisaria) & potato & Giza177 & $30^{\circ} 59^{\prime} 18^{\prime \prime} \mathrm{N}$ and $31^{\circ} 12^{\prime} 19^{\prime \prime} \mathrm{E}$ \\
\hline 9 & GH Kafr (Alzaiat-Dema) & wheat & Sakha101 & $30^{\circ} 47^{\prime} 59^{\prime \prime} \mathrm{N}$ and $30^{\circ} 52^{\prime} 27^{\prime \prime} \mathrm{E}$ \\
\hline \multicolumn{5}{|c|}{ Season 2010} \\
\hline 10 & KF (Metobas-Alkony) & wheat & Sakha104 & $31^{\circ} 21^{\prime} 1^{\prime \prime} \mathrm{N}$ and $30^{\circ} 37^{\prime} 32^{\prime \prime} \mathrm{E}$ \\
\hline 11 & KF (Dessouk-Algamalya) & wheat & Sakha105 & $31^{\circ} 7^{\prime} 42^{\prime \prime} \mathrm{N}$ and $30^{\circ} 38^{\prime} 46^{\prime \prime} \mathrm{E}$ \\
\hline 12 & KF (Dessouk-Dessouk) & clover & Sakha104 & $31^{\circ} 7^{\prime} 42^{\prime \prime} \mathrm{N}$ and $30^{\circ} 38^{\prime} 46^{\prime \prime} \mathrm{E}$ \\
\hline 13 & KF (Qalien-Shabas Emeir) & wheat & Giza177 & $31^{\circ} 5^{\prime} 48^{\prime \prime} \mathrm{N}$ and $30^{\circ} 47^{\prime} 33^{\prime \prime} \mathrm{E}$ \\
\hline 14 & KF (Alread-Kobri Alzawia) & wheat & Sakha102 & $31^{\circ} 15^{\prime} 38^{\prime \prime} \mathrm{N}$ and $31^{\circ} 2^{\prime} 8^{\prime \prime} \mathrm{E}$ \\
\hline
\end{tabular}

GH: Gharbia governorate; KF: Kafr Elsheikh governorate; *Sub-plot area $20 \mathrm{~m}^{2}$

Pure cultures of the indigenous strains of Nostoc, Pseudomonas and Rhizobium were grown on malate $\mathrm{N}$-free [11] and yeast extract mannitol (YEM) medium, respectively. For Rhizobium and Pseudomonas, broth cultures were grown at $29+0.5^{\circ} \mathrm{C}$ on a rotary shaker at $150 \mathrm{rpm}$ for 4 days to a population density of around $10^{9}$ $\mathrm{CFU} / \mathrm{ml}$. The Nostoc culture was incubated under synthetic illumination with a 14 hrs. photoperiod for 10 days. Peat-based carrier for the Rhizobium or Pseudomonas inoculants was neutralized to $\mathrm{pH} 7$ from its original acidity of $\mathrm{pH}$ of $5.0-5.5$ using $5 \%(\mathrm{w} / \mathrm{w})$ powdered $\mathrm{CaCO}_{3}$, then thoroughly mixed and pasteurized at $80^{\circ} \mathrm{C}$ for $4 \mathrm{~h}$ to kill heat-sensitive antagonists, then added to the carrier at a ratio of $520 \mathrm{ml}$ culture $/ \mathrm{kg}$ peat $/ \mathrm{CaCO}_{3}$ mixture. The mixture was thoroughly stirred, cured at room temperature for $24 \mathrm{~h}$, packed, sealed and shelf-stored in a cool dry room at $\sim 18^{\circ} \mathrm{C}$. For quality control tests, the viable population densities of the Rhizo- bium and Pseudomonas inoculants were measured by plate counts on their corresponding media after incubation for 4 days at $29+$ $0.5^{\circ} \mathrm{C}$. For the cyanobacterial inoculant, the "Indian open-air culture method" [17] was followed. Ten samples of the soil-based inoculant were examined for their cyanobacterial CFU densities using decimal dilutions and the most probable number (MPN) test. They contained around $10^{6}-10^{7}$ cyanobacterial filaments (each of 30-70 cells) / $g$ at the time of inoculation of the rice field.

Field experimentation comprised P-fertilization by calcium superphosphate $\left(15 \% \mathrm{P}_{2} \mathrm{O}_{5}\right)$ broadcasted before the third soil leveling under water, eight inoculation treatments (including one uninoculated control) as the sub-plot treatments confined inoculation with: 1) Rhizobium leguminosarum bv. trifolii strain E11;2) Pseudomonas stutzeri strain ERP1; 3) Nostoc sp. strain ERC4; 4) two-strain conso- 
rtium containing the Rhizobium and Pseudomonas strains; 5) twostrain consortium containing the Rhizobium and Nostoc strains; 6) two-strain consortium containing the Pseudomonas and Nostoc strains, 7) three-strain consortium containing the three strains, in addition to the non-inoculation control. Four replications were established for each sub-plot treatment (total of $3 \times 8 \times 4=96$ subplots each of $20 \mathrm{~m}^{2}$ for each of the 14 experimental fields). The inoculants contained the Rhizobium or Pseudomonas strain (each as $720 \mathrm{~g}$ peat-based inoculum/ha) or the Nostoc strain (as $10 \mathrm{~kg}$ soil-based inoculum/ha) were applied by manual broadcasting on the flood water surface at 4 days after transplantation of the rice seedlings. The preparations were equally spread onto the confined subplot areas from outside their borders during a windless calm period at sunset to minimize cross-contamination between the subplots and exposure of viable inoculant populations to lethal effects of direct sunlight. For the consortia sub-treatments, each inoculant preparation containing a single strain was applied separately and simultaneously. Irrigation was withheld for 4 days after inoculation for seedling root establishment while mining for water. The N-fertilization main-plot treatments were 48,96 or $144 \mathrm{~kg} \mathrm{~N} /$ ha applied as urea $(46 \% \mathrm{~N})$, each added in two equal doses, 15 and 30-35 days after transplantation. The water head level at the time of $\mathrm{N}$ fertilization did not exceeded $3 \mathrm{~cm}$. Irrigation was withheld for 3 - 4 days that followed fertilizer application. Those three doses represent $1 / 3,2 / 3$ or the full amount of fertilizer- $\mathrm{N}$, respectively, as recommended by the Field Crops Research Institute, Agriculture Research Centre - Egypt [(http://www.fcri-egypt.org/AboutFCRI. $\mathrm{htm}$ ). (Accessed 20 June 2019)] for maximum grain yield of the 6 rice cvs used. Potassium sulphate $\left(48 \% \mathrm{~K}_{2} \mathrm{O}\right)$ was broadcasted at the rate of $240 \mathrm{~kg} /$ ha equally on all field subplots at one month after transplantation. When necessary, manual weeding and/ or the recommended fungicide and insecticide were applied as common treatment(s) for the entire experimental field area. Water was supplied regularly to maintain a standing water head starting initially at $3 \mathrm{~cm}$ at the seedling transplantation, and was subsequently increased to $10-12 \mathrm{~cm}$ according to the plant development stage. Water supplement was withheld 15 days before harvest. The remaining field area was cultivated with the same rice cv and completely maintained by the farmer using his traditional field management practices.

After maturity, paddy grain yield and the above ground straw vegetation were measured from the entire area of each of the 96 subplots of the experiment (no quadrating or subsampling). The harvest index (\% paddy yield / above ground plant biomass) and the agronomic fertilizer $\mathrm{N}$-use efficiency (kg grain yield/kg fertilizer-N applied) were calculated. Simultaneously, the grain yields of twelve randomly-distributed quadrats (each of $12 \mathrm{~m}^{2}$ ) were measured from the adjacent non-inoculated field areas cultivated by the same rice cultivar and entirely managed by the farmer without interference from the research team (except if the farmer asked for advice). The mean weight of grain yield/ha calculated from the farmer's 12 samples is referred to as the "farmer's yield".

\section{Statistical analysis}

Large differences in environmental, agro-ecological variables existed among the 14 separated field test sites distributed within wide areas of the Nile delta and with different geographical and edaphic properties. Individually for each experiment, the splitplot statistical design and the least significant differences (LSD) at the confidence level of $95 \%$ were used to evaluate the significance of the differences that related to the main $\mathrm{N}$ fertilization treatments, the inoculation treatments and the first order interaction between them. The data were analyzed using the "IRRISTAT" program version 4.3 (The International Rice Research Institute, Manila, The Philippines) [(http://agris.fao.org/agris-search/search. do?recordID=PH1998010400). (Accessed 20 June 2019)]. Multivariate statistical analyses were performed using Clustan Graphics for cluster analysis ver. 8.02 [(https://link.springer.com/chapter/10.1007/978-3-642-60187-3_27. (Accessed 20 June 2019)].

\section{Results}

Lab and greenhouse results

\section{Isolation of rice endophytes}

Consistent with the Azospirillum growth behavior, inoculation of surface-sterilized rice root macerates into the semisolid tube deeps of the enrichment medium [11] yielded turbidity of bacterial growth at the subsurface microaerophilic region. Subsurface growth from the tube cultures was re-streaked on agar plates of the same medium. Twenty-one isolated colonies with the characteristics of Azospirillum (pink pigmented colonies of Gram negative short rods on beef extract peptone agar plates) were picked, re-streaked and stocked in pure cultures. Cyanobacterial isolates were also obtained and stocked for identification.

\section{Isolates identification}

The taxonomic affinities of the 21 pure culture isolates obtained by selection on the $\mathrm{N}$-free malate medium were examined by 
Differential Performance of Individual and Consortial Endophytes for Enhanced Rice Yield and Agronomic N-Use Efficiency in Open-Fields in the Nile Delta

the sequence similarity of phylogenetically discrete PCR-amplified segments of their 16s rRNA encoding gene. Their closest $(\geq$ 97\%) sequence matches with greatest taxonomic affinity were distributed as follows: 14 Pseudomonas, 3 Brevundimonas, 2 Stenotrophomonas, 1 member of Rhodobacteriaceae, and 1 unclassified Bacterium. Further evaluation of the most abundant group of 14 isolates with taxonomic affinity for Pseudomonas indicated the following: 4 had 1.000 similarity indices to P. stutzeri strains ATCC 17588, DSM 5190T, AJ63355, and AJ288151; 5 others had 0.990 - 0.985 similarity indices to P. stutzeri strains ATCC 17589, IARI-L-119, G2C, DSM 5190T, and ATCC 27951; 4 had a similarity index of 1.000 with taxonomic affinity to other Pseudomonas species (Pseudomonas fluorescens D11188, P. putida strains D26, D21 and EF204233), and 1 had a 1.000 similarity index to an unclassified species of Pseudomonas sp. strain WH060. One of the isolates with taxonomic affinity for Pseudomonas stutzeri (sequence similarity index of 1.000 with strain ATCC 17588) was chosen for this study and assigned the strain designation of ERP1 (Egypt Rice Pseudomonas 1).

The sequence analysis of the 16s rRNA encoding gene for 4 cyanobacterial isolates indicated that each of them had taxonomic affiliation with the class and phylum Cyanobacteria, Family 1 and group GP1. The sequence match with the highest similarity index (0.908) was with Nostoc sp. strain PCC 9426. Other matches with similarity indices between 0.785 - 0.829 had sequence similarities with 5 other Nostoc strains (HK-01, CEN21, PCC 6720, LPUL 424, PPEZ 426), and with one isolate of Anabaenopsis circularis strain NIES 21. The cyanobacterial isolate selected for this study was the one with the highest sequence similarity index of 0.908 with Nostoc sp. strain PCC9426 [assigned the designation of ERC4 (Egypt Rice Cyanobacterium 4)]. CMEIAS computer-assisted microscopy of this test strain indicated long bent filamentous chains of spherical vegetative cells with a diameter of $2.32 \pm 0.13 \mu \mathrm{m}$, a roundness shape index of $0.823 \pm 0.057$, and with $23.7 \pm 1.0$ vegetative cells separating round intercalary and terminal heterocyst cells having a larger diameter of $3.38 \pm 0.23 \mu \mathrm{m}$ in the same chain (Figure1 in "Online Resource"). Its morphology resembles the photomicrograph of Nostoc available at: https://www.google.com/ search?q=Nostoc + morphology\&source $=$ lnms\&tbm $=$ isch \&sa $=X \&-$ ved=0ahUKEwj3oev6ge3dAhWI7IMKHa0mBZMQ_AUIDigB\&biw=1632\&bih=815\#imgdii=R500FHvNHZAu1M:\&imgrc $=i x x j-$ 5D7wtYhigM (Accessed 20 June 2019). This site contains further information about this genus.

\section{Test for biosafety of the cyanobacterial strain}

The cyanobacteria, in particular, should definitely be tested for production of microcystins toxins before use in open fields [18]. We used the enzyme-linked immunosorbent assay [13] to determine if the chosen cyanobacterium ERC4 strain produces these toxins. The result was negative, excluding that risk for its open field application.

Assessment of rice growth-promotion under gnotobiotic conditions

Figure $2 \mathrm{a}-\mathrm{d}$ shows the growth responses of 4 rice cvs to single-strain inoculation with the Pseudomonas ERP1 and the Nostoc ERC4 in gnotobiotic tube culture assay. Strain ERP1 promoted plant growth whereas inoculation with the cyanobacterial strain ERC4, individually or in consortia, inhibited growth of seedlings of the 4 rice cvs under the same conditions. This adverse effect of the Nostoc ERC4 was confirmed in comparison to the positive effect of inoculation with Rhizobium E11 (Table 2), validating the performance of this rhizobial strain on various rice cvs $[8,9]$. Likely reasons for this growth inhibition by the Nostoc isolate under gnotobiotic conditions are addressed later in the context. Integration of Figure 2a-d, Figure 2 in "Online Resource" and Table 2, in addition to previously recorded results [8,9], clearly show the differential performance of the three inoculant test microorganisms and some of their consortia in promotion (or inhibition) of rice growth in gnotobiotic assessments.
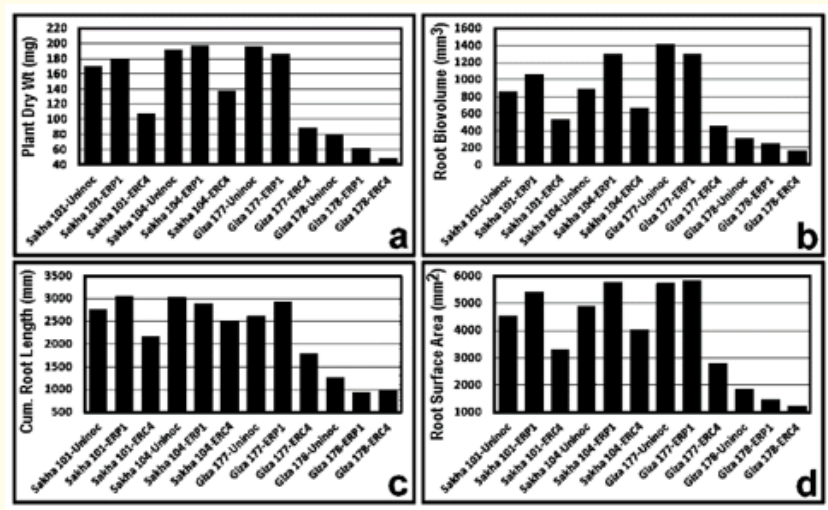

Figure 2a-2d: Growth responses of 4 rice cultivars inoculated with single-strains of Pseudomonas sp. ERP1 or Nostoc sp. ERC4 or a consortium containing both of them. Growth parameters were (a) plant dry weight, (b) root biovolume, (c) cumulative root length and (d) root surface area. 
Differential Performance of Individual and Consortial Endophytes for Enhanced Rice Yield and Agronomic N-Use Efficiency in Open-Fields in the Nile Delta

Table 2: Effect of inoculation with Rhizobium leguminosarum bv. trifolii E11 and Nostoc sp. ERC4 on root biovolume and shoot height of four rice cultivars (cvs) grown under gnotobiotic conditions.

\begin{tabular}{|l|c|c|c|}
\hline Rice cv & $\begin{array}{c}\text { Bacterial } \\
\text { Inoculum }\end{array}$ & $\begin{array}{c}\text { Root biovolume } \\
\mathbf{( m m}^{3} \mathbf{)}\end{array}$ & $\begin{array}{c}\text { Shoot } \\
\text { height } \\
\text { (mm) }\end{array}$ \\
\hline Sakha 101 & Uninoculated & $600 \pm 231$ & $280 \pm 15$ \\
\hline Sakha 101 & R. leg trifolii E11 & $1100 \pm 141$ & $284 \pm 0$ \\
\hline Sakha 101 & ERC4 & $575 \pm 50$ & $259 \pm 12$ \\
\hline Sakha 101 & Rlt E11 + ERC4 & $640 \pm 55$ & $275 \pm 13$ \\
\hline Sakha 104 & Uninoculated & $650 \pm 129$ & $311 \pm 12$ \\
\hline Sakha 104 & R. leg trifolii E11 & $1020 \pm 110$ & $300 \pm 8$ \\
\hline Sakha 104 & ERC4 & $820 \pm 45$ & $284 \pm 2$ \\
\hline Sakha 104 & Rlt E11 + ERC4 & $820 \pm 84$ & $286 \pm 8$ \\
\hline Giza 177 & Uninoculated & $1067 \pm 115$ & $295 \pm 14$ \\
\hline Giza 177 & R. leg trifolii E11 & $1000 \pm 82$ & $283 \pm 14$ \\
\hline Giza 177 & ERC4 & $450 \pm 129$ & $271 \pm 19$ \\
\hline Giza 177 & Rlt E11 + ERC4 & $875 \pm 150$ & $300 \pm 15$ \\
\hline Giza 178 & Uninoculated & $325 \pm 50$ & $250 \pm 23$ \\
\hline Giza 178 & R. leg trifolii E11 & $550 \pm 100$ & $550 \pm 274$ \\
\hline Giza 178 & ERC4 & $300 \pm 0$ & $300 \pm 219$ \\
\hline Giza 178 & Rlt E11 + ERC4 & $400 \pm 71$ & $400 \pm 222$ \\
\hline
\end{tabular}

\section{Field results}

The entire raw dataset and results of their statistical evaluations for the field inoculation tests are accessible in Tables 1 through 14 in the "Online Recourse". To simplify presentation of the results, Tables 3 through 8 and Figures 3 through 7 provide supportive data indicating the tendencies from which our conclusions could be extracted.

\section{Paddy yield}

Table 3 shows changes of paddy grain yield in the 14 experimental field locations with application of fertilizer- $\mathrm{N}$ at 48, 96 and $144 \mathrm{~kg} \mathrm{~N} / \mathrm{ha}$ with and without inoculation treatments. The yield responses to application of the 7 biofertilization treatments vs. their corresponding non-inoculated control are presented in Table 4. Significant percentage increases due to inoculation with the rhizobial strain E11 alone were achieved in 5 of the 14 experiments, in 7 experiments by inoculation with the Pseudomonas strain ERP1 alone and in 8 experiments by inoculation with the cyanobacterial strain ERC4 alone. Increased grain yields were also obtained by inoculation with dual or triple consortia strains in 6 experimental locations. Significant increases in grain yield with inoculation occurred in 13 over the 14 experiments even when accompanied with application of the highest dose of $144 \mathrm{~kg}$ fertilizer-N/ha. The experiment no. 4 was an exception in that only the triple strain consortium achieved a non-significant increase in grain yield. However, there was no indication either visibly or extracted from the collected data that rice productivity was adversely affected under field conditions by any of these single-strain inoculations. The yield responses following single-strain and various consortia biofertilization were always greater than the corresponding uninoculated controls.

The highest paddy yield obtained with the best experimental treatment applied to each field location considerably exceeded the yield obtained simultaneously in the adjacent field area using the same plant cv and entirely managed by the farmer according to his conventional agronomic practices (Table 5, Figure 3). Considering all the 14 experiments, the mean of grain yield without inoculation was 9.254 tons/ha and increased with biofertilization to 10.274 tons/ha. The mean yield in the 14 adjacent farmers' field areas was only 8.062 tons/ha. Even without inoculation, the mean yield of the best treatments in the experimental plots exceeded those obtained by the farmers by 1.192 tons/ha (14.8\%), and further by 2.212 tons/ha (27.4\%) with adoption of the biofertilization technology. Also, the data of Tables 3, 4 and 5 indicate that the rice cvs differed in their response to each of the inoculation treatments.

\section{Straw production}

Straw production, as shown in Table 6 and Tables 1 through 14 in the "Online Resource", significantly increased concomitantly with the ascending increases of $\mathrm{N}$ application doses, indicating that vegetative growth of rice was $\mathrm{N}$-limited in each of the 14 fields. However, biofertilization significantly increased straw production in 7, 7 and 7 of the 14 experiments when they received urea fertilizer at 48, 96 or $144 \mathrm{~kg} \mathrm{~N} / \mathrm{ha}$, respectively. The magnitude of these increases fluctuated with the different biofertilization treatments. The mean of straw production for the 14 experiments was the lowest $(8.775+2.802$ ton/ha) with biofertilization by the Pseudomonas stutzeri strain ERP1 along with application of $48 \mathrm{~kg}$ $\mathrm{N} / \mathrm{ha}$, and was the highest $(12.537+3.085$ ton/ha) in response to biofertilization with the Nostoc sp. plus $\mathrm{N}$ at $144 \mathrm{~kg} / \mathrm{ha}$. However, inoculation with individual strains increased straw production by 3.50, 4.71 and $7.99 \%$ compared to the corresponding uninoculated controls when accompanied by application of the 48,96 or $144 \mathrm{~kg}$ $\mathrm{N} / \mathrm{ha}$, respectively. The corresponding figures of produced straw following inoculation by consortia containing two or the three microbial candidates were very close $(5.89,5.63$ and $7.43 \%)$, in the same respective order. 
Differential Performance of Individual and Consortial Endophytes for Enhanced Rice Yield and Agronomic N-Use Efficiency in Open-Fields in the Nile Delta

Table 3: Effect of rice* inoculation with an individual strain or a consortium of Rhizobium leguminosarum bv. trifolii strain E11, Pseudomonas stutzeri strain ERP1 or Nostoc sp. strain ERC4 on mean of rice* grain yield (ton/ha) at 14 field locations in the Nile delta during the 2009 and 2010 cultivation seasons.

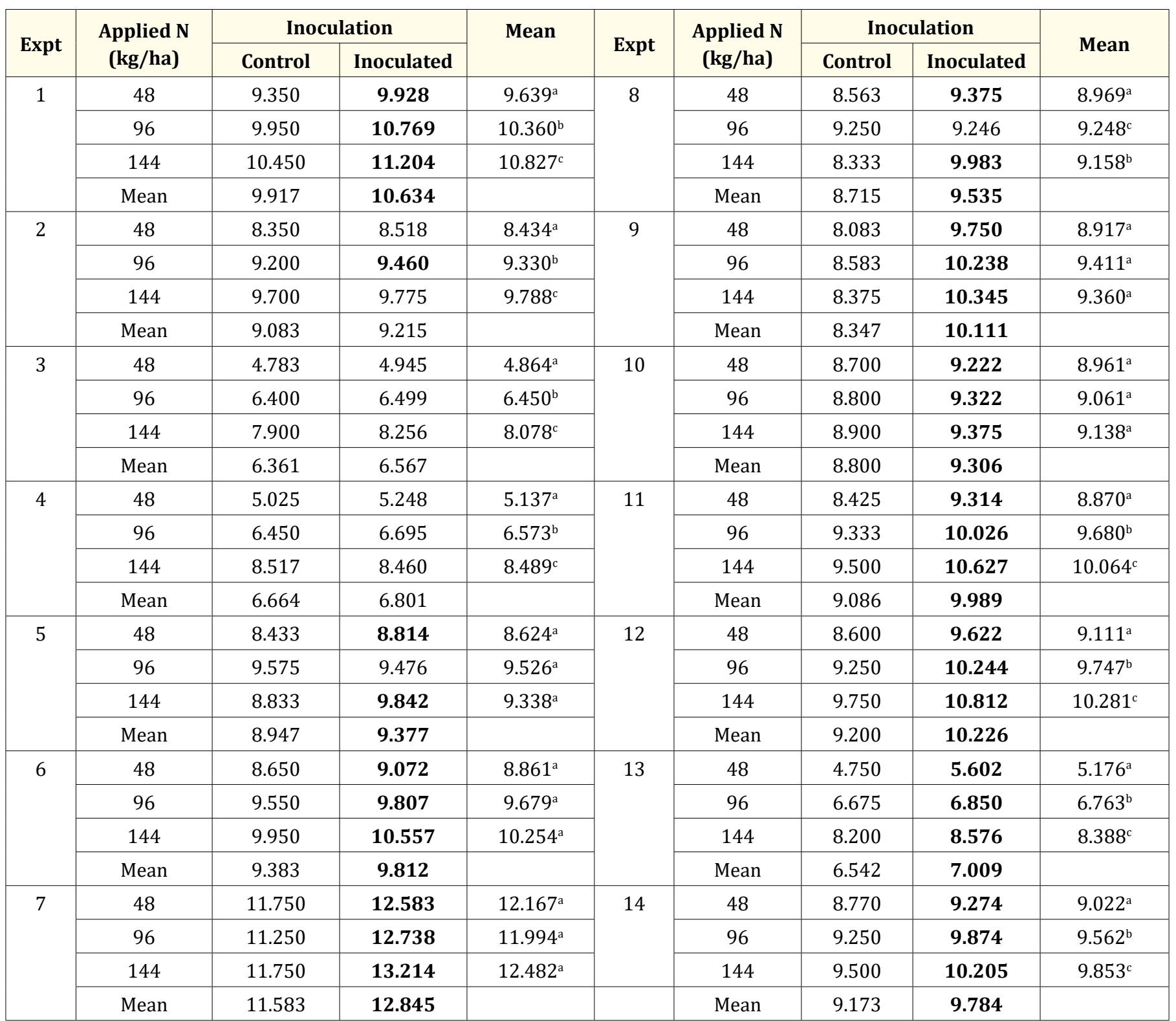

*Oryza sativa cvs: Giza 177 (expts 2, 3, 4, 8, 13), Sakha 101 (expts 7, 9), Sakha 102 (expts 1, 14), Sakha 103 (expts 5, 6), Sakha 104 (expts 10,12 ), Sakha 105 (expt 11). For each experiment, means of grain yield that are superscripted by different bold letters in the same column (for $\mathrm{N}$-fertilization doses), or their values highlighted in bold (for inoculation treatments) are significantly different from the mean of the corresponding uninoculated control at the $95 \%$ confidence level. 
Differential Performance of Individual and Consortial Endophytes for Enhanced Rice Yield and Agronomic N-Use Efficiency in Open-Fields in the Nile Delta

Table 4: Percentage increases $(\Delta)$ in rice yield* over the corresponding non-inoculated controls achieved by inoculation with the individual or consortia strains (Rhizobium leguminosarum bv trifolii strain E11, Pseudomonas stutzeri strain ERP1 and Nostoc sp. strain ERC4).

\begin{tabular}{|c|c|c|c|c|c|c|c|c|c|c|c|}
\hline \multirow{2}{*}{ Expt } & \multirow{2}{*}{$\begin{array}{l}\text { Rice } \\
\text { cv }\end{array}$} & \multirow{2}{*}{$\begin{array}{l}\text { Best experimental } \\
\text { treatment }\end{array}$} & \multicolumn{9}{|c|}{ Grain Yield (tons/ha) and corresponding percentage increases $(\Delta)$} \\
\hline & & & Control & E11 & $\Delta$ & ERP1 & $\Delta$ & ERC4 & $\Delta$ & Consortium & $\Delta$ \\
\hline \multicolumn{12}{|c|}{ Season 2009} \\
\hline 1 & Sakha102 & ERC4+144N & 10.450 & ---- & --- & ---- & ---- & 11.933 & 14.2 & --- & --- \\
\hline 2 & Giza177 & ERC4+144N & 9.700 & $-\cdots-$ & $-\cdots$ & ---- & ---- & 10.050 & 3.6 & $-\cdots-$ & --- \\
\hline 3 & Giza177 & ERP1+ERC4+144N & 7.900 & $-\cdots-$ & $-\cdots$ & 8.133 & 2.9 & 8.300 & 5.1 & 8.425 & 6.6 \\
\hline 4 & Giza177 & E11+ERP1+ERC4+144N & 8.517 & 8.367 & -1.8 & 8.400 & -1.4 & 8.417 & -1.2 & 8.600 & 1.0 \\
\hline 5 & Sakha103 & ERC4+144N & 8.833 & $-\cdots$ & --- & ---- & ---- & 10.517 & 19.1 & $-\cdots-$ & --- \\
\hline 6 & Sakha103 & ERC4+144N & 9.950 & --- & $-\cdots$ & ---- & ---- & 10.800 & 8.5 & $-\cdots$ & ---- \\
\hline 7 & Sakha101 & ERP1+144N & 11.750 & --- & ---- & 13.833 & 17.7 & --- & ---- & --- & --- \\
\hline 8 & Giza177 & ERP1+ERC4+144N & 8.333 & --- & ---- & 10.625 & 27.5 & 9.125 & 9.5 & 10.875 & 30.5 \\
\hline 9 & Sakha101 & ERC4+144N & 8.375 & ---- & --- & --- & ---- & 11.375 & 35.8 & --- & --- \\
\hline \multicolumn{12}{|c|}{ Season 2010} \\
\hline 10 & Sakha104 & $\mathrm{E} 11+144 \mathrm{~N}$ & 8.800 & 9.600 & 7.9 & --- & --- & --- & ---- & --- & --- \\
\hline 11 & Sakha105 & E11+ERP1+ERC4+144N & 9.500 & 10.275 & 8.2 & 10.533 & 10.9 & 10.300 & 8.4 & 10.900 & 14.7 \\
\hline 12 & Sakha104 & E11+ERP1+144N & 9.750 & 10.900 & 11.8 & 10.500 & 7.7 & --- & ---- & 11.250 & 15.4 \\
\hline 13 & Giza177 & E11+ERP1+ERC4+144N & 8.200 & 8.450 & 3.0 & 8.538 & 4.1 & 8.350 & 1.8 & 8.783 & 7.1 \\
\hline 14 & Sakha102 & E11+ERP1+144N & 9.500 & 10.250 & 7.9 & 9.900 & 4.2 & ---- & ---- & 10.450 & 10.0 \\
\hline
\end{tabular}

${ }^{*}$ calculated for the treatments that achieved the highest grain yield in each experiment. The mean yield (values highlighted in bold) is statistically significantly different from its corresponding non-inoculated control at the $95 \%$ confidence level.

Table 5: Comparisons between rice grain yields in the best experimental treatments and those in adjacent fields using the same rice $\mathrm{cv}$ and farmer's practices.

\begin{tabular}{|c|c|c|c|c|c|c|c|c|}
\hline \multirow[t]{2}{*}{ Expt } & \multirow{2}{*}{$\begin{array}{l}\text { Growing } \\
\text { season }\end{array}$} & \multirow{2}{*}{$\begin{array}{c}\text { Rice cv/bacte- } \\
\text { rial strain(s) that } \\
\text { produced the best } \\
\text { experimental grain } \\
\text { yield }\end{array}$} & \multirow{2}{*}{$\begin{array}{c}\text { N } \\
\text { (kg/ } \\
\text { ha) }\end{array}$} & \multicolumn{2}{|c|}{$\begin{array}{c}\text { Best experimental grain } \\
\text { yield (tons/ha) }\end{array}$} & \multirow{2}{*}{$\begin{array}{l}\text { Farmer's grain } \\
\text { yield with no } \\
\text { inoculation } \\
\text { (tons/ha) }\end{array}$} & \multicolumn{2}{|c|}{$\begin{array}{c}\% \text { increase over the farm- } \\
\text { er's grain yield }\end{array}$} \\
\hline & & & & Non-inoculated & Inoculated & & No inoculation & Inoculation \\
\hline 1 & \multirow{9}{*}{2009} & Sakha 102 + ERC4 & 144 & 10.450 & 11.933 & 9.520 & 9.8 & 25.3 \\
\hline 2 & & Giza 177 + ERC4 & 144 & 9.700 & 10.050 & 6.188 & 56.8 & 62.4 \\
\hline 3 & & $\begin{array}{c}\text { Giza } 177+ \\
\text { ERP1+ERC4 }\end{array}$ & 144 & 7.900 & 8.425 & 6.188 & 27.7 & 36.2 \\
\hline 4 & & $\begin{array}{c}\text { Giza } 177+ \\
\text { E11+ERP1+ERC4 }\end{array}$ & 144 & 8.517 & 8.600 & 6.545 & 30.1 & 31.4 \\
\hline 5 & & Sakha 103 + ERC4 & 144 & 8.833 & 10.517 & 8.588 & 2.9 & 22.5 \\
\hline 6 & & Sakha 103 + ERC4 & 144 & 9.950 & 10.800 & 9.044 & 10.0 & 19.4 \\
\hline 7 & & Sakha 101 + ERP1 & 144 & 11.750 & 13.833 & 9.520 & 23.4 & 17.7 \\
\hline 8 & & $\begin{array}{c}\text { Giza } 177+ \\
\text { ERP1+ERC4 }\end{array}$ & 144 & 8.333 & 10.875 & 10.625 & ---- & 2.4 \\
\hline 9 & & Sakha 101 + ERC4 & 144 & 8.375 & 11.375 & 7.140 & 17.3 & 59.3 \\
\hline 10 & \multirow{5}{*}{2010} & Sakha 104 + E11 & 144 & 8.800 & 9.600 & 7.854 & 12.0 & 22.2 \\
\hline 11 & & $\begin{array}{c}\text { Sakha } 105+ \\
\text { E11+ERP1+ERC4 }\end{array}$ & 144 & 9.500 & 10.900 & 8.687 & 9.4 & 25.5 \\
\hline 12 & & $\begin{array}{c}\text { Sakha } 104+ \\
\text { E11+ERP1 }\end{array}$ & 144 & 9.750 & 11.250 & 8.092 & 20.5 & 39.0 \\
\hline 13 & & $\begin{array}{c}\text { Giza } 177+ \\
\text { E11+ERP1+ERC4 }\end{array}$ & 144 & 8.200 & 8.783 & 6.426 & 27.6 & 36.7 \\
\hline 14 & & $\begin{array}{l}\text { Sakha } 102+ \\
\text { E11+ERP1 }\end{array}$ & 144 & 9.500 & 10.450 & 8.449 & 12.4 & 23.7 \\
\hline \multicolumn{4}{|c|}{ Mean all over the field experimentation program } & 9.254 & 10.274 & 8.062 & 20.0 & 30.3 \\
\hline \multicolumn{4}{|c|}{ SD (5\%) } & 1.045 & 1.117 & 1.400 & 13.9 & 15.9 \\
\hline
\end{tabular}

Means highlighted in bold are significantly different from their corresponding non-inoculated control (at the 95\% confidence level) 


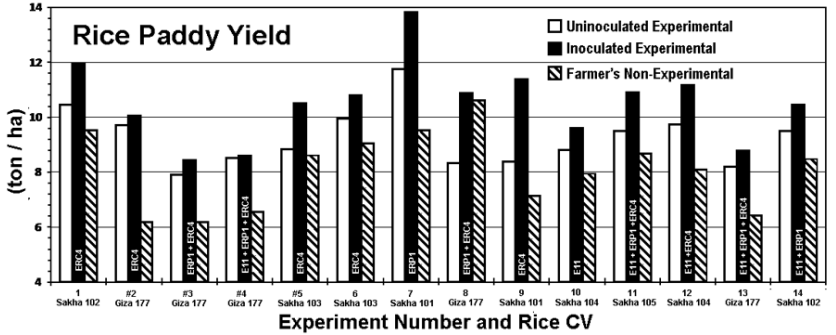

Figure 3: Best paddy grain yield, responding rice cultivar and biofertilizer formulation obtained at 14 field locations with and without inoculation under optimal agronomic conditions vs. farmers' non-experimental treatment.
Harvest index

Non-significant increases in the harvest index (\% paddy yield/ above ground biomass at harvest) were obtained with increased $\mathrm{N}$-fertilizer application without inoculation (Table 7, Tables 1 - 14 in the "Online Resource"). Maximum percentage increases of 16.9, 14.2 and $7.8 \%$ in the harvest indices were obtained by individual strain inoculation with the Pseudomonas stutzeri (ERP1) recognized with application of the 48,96 or $144 \mathrm{~kg} \mathrm{~N} / \mathrm{ha}$, respectively. Interestingly, when combined into a consortial inoculant with one or both of the other candidates, this Pseudomonas strain did not exert the same vegetative growth enhancement effect. This unexpected finding justifies further investigation to explore why inoculation with this strain alone or within consortia extorted different responses.

Table 6: Effect of rice* inoculation with an individual strain or consortia of Rhizobium leguminosarum bv. trifolii strain E11, Pseudomonas stutzeri strain ERP1 or Nostoc sp. strain ERC4 on straw yield (ton/ha) at 14 field locations in the Nile delta during the 2009 and 2010 cultivation seasons.

\begin{tabular}{|c|c|c|c|c|c|c|c|c|c|}
\hline \multirow{2}{*}{ Expt } & \multirow{2}{*}{$\begin{array}{c}\text { Applied N } \\
\text { (kg/ha) }\end{array}$} & \multicolumn{2}{|c|}{ Inoculation } & \multirow[t]{2}{*}{ Mean } & \multirow{2}{*}{ Expt } & \multirow{2}{*}{$\begin{array}{c}\text { Applied N } \\
\text { (kg/ha) }\end{array}$} & \multicolumn{2}{|c|}{ Inoculation } & \multirow{2}{*}{ Mean } \\
\hline & & Control & Inoculated & & & & Control & Inoculated & \\
\hline \multirow[t]{4}{*}{1} & 48 & 10.033 & 9.724 & $9.879^{\mathrm{a}}$ & \multirow[t]{4}{*}{8} & 48 & 12.750 & 15.988 & $14.369^{\mathrm{a}}$ \\
\hline & 96 & 10.217 & 11.389 & $10.80^{3} \mathrm{a}$ & & 96 & 16.500 & 17.149 & $16.825^{\mathrm{a}}$ \\
\hline & 144 & 11.250 & 11.560 & $11.405^{\mathrm{a}}$ & & 144 & 15.000 & 16.809 & $15.905^{\mathrm{a}}$ \\
\hline & Mean & 10.500 & 10.891 & & & Mean & 14.750 & 16.649 & \\
\hline \multirow[t]{4}{*}{2} & 48 & 9.150 & 9.389 & $9.270^{\mathrm{a}}$ & \multirow[t]{4}{*}{9} & 48 & 7.000 & 8.126 & $7.563^{\mathrm{a}}$ \\
\hline & 96 & 9.711 & 10.038 & $9.875^{\mathrm{b}}$ & & 96 & 8.000 & 8.104 & $8.052^{\mathrm{b}}$ \\
\hline & 144 & 10.300 & 10.913 & $10.607^{\mathrm{c}}$ & & 144 & 6.592 & 8.902 & $7.747^{\mathrm{ab}}$ \\
\hline & Mean & 9.720 & 10.113 & & & Mean & 7.197 & 8.377 & \\
\hline \multirow[t]{4}{*}{3} & 48 & 7.483 & 7.517 & $7.500^{\mathrm{a}}$ & \multirow[t]{4}{*}{10} & 48 & 16.833 & 15.631 & $16.232^{\mathrm{a}}$ \\
\hline & 96 & 8.967 & 9.079 & $9.023^{\mathrm{b}}$ & & 96 & 15.667 & 15.387 & $15.527^{\mathrm{a}}$ \\
\hline & 144 & 10.617 & 10.596 & $10.607^{\mathrm{c}}$ & & 144 & 15.250 & 15.673 & $15.462^{\mathrm{a}}$ \\
\hline & Mean & 9.022 & 9.064 & & & Mean & 15.917 & 15.564 & \\
\hline \multirow[t]{4}{*}{4} & 48 & 7.975 & 7.964 & $7.970^{\mathrm{a}}$ & \multirow[t]{4}{*}{11} & 48 & 9.150 & 9.148 & $9.149^{a}$ \\
\hline & 96 & 9.525 & 9.460 & $9.493^{\mathrm{b}}$ & & 96 & 9.150 & 9.195 & $9.168^{\mathrm{a}}$ \\
\hline & 144 & 11.050 & 10.922 & $10.986^{c}$ & & 144 & 9.250 & 9.336 & $9.293^{\mathrm{a}}$ \\
\hline & Mean & 9.517 & 9.449 & & & Mean & 9.183 & 9.226 & \\
\hline \multirow[t]{4}{*}{5} & 48 & 11.550 & 11.987 & $11.769^{\mathrm{a}}$ & \multirow[t]{4}{*}{12} & 48 & 12.275 & 12.636 & $12.456^{\mathrm{a}}$ \\
\hline & 96 & 12.325 & 12.188 & $12.257^{\mathrm{b}}$ & & 96 & 12.750 & 13.369 & $13.060 \mathrm{~b}^{\mathrm{a}}$ \\
\hline & 144 & 11.700 & 12.487 & $12.094^{\mathrm{b}}$ & & 144 & 13.083 & 14.012 & $13.548^{c}$ \\
\hline & Mean & 11.858 & 12.221 & & & Mean & 12.703 & 13.339 & \\
\hline \multirow[t]{4}{*}{6} & 48 & 11.700 & 12.277 & $11.989^{a}$ & \multirow[t]{4}{*}{13} & 48 & 11.925 & 13.124 & $12.525^{\mathrm{a}}$ \\
\hline & 96 & 12.325 & 12.507 & $12.416^{\mathrm{b}}$ & & 96 & 12.967 & 13.829 & $13.398^{\mathrm{a}}$ \\
\hline & 144 & 12.575 & 13.023 & $12.799^{c}$ & & 144 & 13.583 & 14.600 & $14.092^{\mathrm{a}}$ \\
\hline & Mean & 12.200 & 12.602 & & & Mean & 12.825 & 13.851 & \\
\hline \multirow[t]{4}{*}{7} & 48 & 7.483 & 7.517 & $7.500^{\mathrm{a}}$ & \multirow[t]{4}{*}{14} & 48 & 7.425 & 7.735 & $7.580^{\mathrm{a}}$ \\
\hline & 96 & 8.967 & 9.079 & $9.023^{\mathrm{b}}$ & & 96 & 9.125 & 9.398 & $9.262^{\mathrm{b}}$ \\
\hline & 144 & 10.617 & 10.596 & $10.607^{c}$ & & 144 & 10.900 & 11.022 & $10.961^{c}$ \\
\hline & Mean & 9.022 & 9.064 & & & Mean & 9.150 & 9.385 & \\
\hline
\end{tabular}

*Oryza sativa cvs: Giza 177 (expts 2,3,8,13), Sakha 101 (expts 7,9), Sakha 102 (expts 1, 14), Sakha 103 (expts 5, 6), Sakha 104 (expts10,12),Sakha105 (expt11).Foreachexperiment,meansofstrawproductionsuperscripted bydifferentlettersinthesame column (forN-fertilization doses) or theirvalueshighlighted inbold(for inoculationtreatments)aresignificantly differentfrom the mean of the corresponding uninoculated control at the $95 \%$ confidence level. 
Differential Performance of Individual and Consortial Endophytes for Enhanced Rice Yield and Agronomic N-Use Efficiency in Open-Fields in the Nile Delta

Table 7: Effect of rice* inoculation with an individual strain or consortia of Rhizobium leguminosarum bv. trifolii strain E11, Pseudomonas stutzeri strain ERP1 or Nostoc sp. strain ERC4 on the rice harvest index* at 14 field locations in the Nile delta during the 2009 and 2010 cultivation seasons.

\begin{tabular}{|c|c|c|c|c|c|c|c|c|c|}
\hline \multirow[t]{2}{*}{ Expt } & \multirow{2}{*}{$\begin{array}{l}\text { Applied N } \\
\text { (kg/ha) }\end{array}$} & \multicolumn{2}{|c|}{ Inoculation } & \multirow[b]{2}{*}{ Mean } & \multirow[t]{2}{*}{ Expt } & \multirow{2}{*}{$\begin{array}{l}\text { Applied N } \\
\text { (kg/ha) }\end{array}$} & \multicolumn{2}{|c|}{ Inoculation } & \multirow[t]{2}{*}{ Mean } \\
\hline & & Control & Inoculated & & & & Control & Inoculated & \\
\hline \multirow[t]{4}{*}{1} & 48 & 48.5 & 50.6 & $49.6^{a}$ & \multirow[t]{4}{*}{8} & 48 & 48.0 & 44.1 & $46.1^{\mathrm{a}}$ \\
\hline & 96 & 49.3 & 48.6 & $49.0^{\mathrm{a}}$ & & 96 & 40.5 & 42.8 & $41.7^{\mathrm{a}}$ \\
\hline & 144 & 48.2 & 49.3 & $48.8^{\mathrm{a}}$ & & 144 & 43.9 & 44.2 & $44.1^{\mathrm{a}}$ \\
\hline & Mean & 48.7 & 49.5 & & & Mean & 44.1 & 43.7 & \\
\hline \multirow[t]{4}{*}{2} & 48 & 48.5 & 50.6 & $49.6^{a}$ & \multirow[t]{4}{*}{9} & 48 & 48.0 & 44.1 & $46.1^{\mathrm{a}}$ \\
\hline & 96 & 49.3 & 48.6 & $49.0^{\mathrm{a}}$ & & 96 & 40.5 & 42.8 & $41.7^{\mathrm{a}}$ \\
\hline & 144 & 48.2 & 49.3 & $48.8^{\mathrm{a}}$ & & 144 & 43.9 & 44.2 & $44.1^{\mathrm{a}}$ \\
\hline & Mean & 48.7 & 49.5 & & & Mean & 44.1 & 43.7 & \\
\hline \multirow[t]{4}{*}{3} & 48 & 48.5 & 50.6 & $49.6^{a}$ & \multirow[t]{4}{*}{10} & 48 & 48.0 & 44.1 & $46.1^{\mathrm{a}}$ \\
\hline & 96 & 49.3 & 48.6 & $49.0^{\mathrm{a}}$ & & 96 & 40.5 & 42.8 & $41.7^{\mathrm{a}}$ \\
\hline & 144 & 48.2 & 49.3 & $48.8^{\mathrm{a}}$ & & 144 & 43.9 & 44.2 & $44.1^{\mathrm{a}}$ \\
\hline & Mean & 48.7 & 49.5 & & & Mean & 44.1 & 43.7 & \\
\hline \multirow[t]{4}{*}{4} & 48 & 48.5 & 50.6 & $49.6^{a}$ & \multirow[t]{4}{*}{11} & 48 & 48.0 & 44.1 & $46.1^{\mathrm{a}}$ \\
\hline & 96 & 49.3 & 48.6 & $49.0^{\mathrm{a}}$ & & 96 & 40.5 & 42.8 & $41.7^{\mathrm{a}}$ \\
\hline & 144 & 48.2 & 49.3 & $48.8^{\mathrm{a}}$ & & 144 & 43.9 & 44.2 & $44.1^{\mathrm{a}}$ \\
\hline & Mean & 48.7 & 49.5 & & & Mean & 44.1 & 43.7 & \\
\hline \multirow[t]{4}{*}{5} & 48 & 48.5 & 50.6 & $49.6^{a}$ & \multirow[t]{4}{*}{12} & 48 & 48.0 & 44.1 & $46.1^{\mathrm{a}}$ \\
\hline & 96 & 49.3 & 48.6 & $49.0^{\mathrm{a}}$ & & 96 & 40.5 & 42.8 & $41.7^{\mathrm{a}}$ \\
\hline & 144 & 48.2 & 49.3 & $48.8^{\mathrm{a}}$ & & 144 & 43.9 & 44.2 & $44.1^{\mathrm{a}}$ \\
\hline & Mean & 48.7 & 49.5 & & & Mean & 44.1 & 43.7 & \\
\hline \multirow[t]{4}{*}{6} & 48 & 48.5 & 50.6 & $49.6^{a}$ & \multirow[t]{4}{*}{13} & 48 & 48.0 & 44.1 & $46.1^{\mathrm{a}}$ \\
\hline & 96 & 49.3 & 48.6 & $49.0^{\mathrm{a}}$ & & 96 & 40.5 & 42.8 & $41.7^{\mathrm{a}}$ \\
\hline & 144 & 48.2 & 49.3 & $48.8^{\mathrm{a}}$ & & 144 & 43.9 & 44.2 & $44.1^{\mathrm{a}}$ \\
\hline & Mean & 48.7 & 49.5 & & & Mean & 44.1 & 43.7 & \\
\hline \multirow[t]{4}{*}{7} & 48 & 48.0 & 44.1 & $46.1^{\mathrm{a}}$ & \multirow[t]{4}{*}{14} & 48 & 48.0 & 44.1 & $46.1^{\mathrm{a}}$ \\
\hline & 96 & 40.5 & 42.8 & $41.7^{\mathrm{a}}$ & & 96 & 40.5 & 42.8 & $41.7^{\mathrm{a}}$ \\
\hline & 144 & 43.9 & 44.2 & $44.1^{\mathrm{a}}$ & & 144 & 43.9 & 44.2 & $44.1^{\mathrm{a}}$ \\
\hline & Mean & 44.1 & 43.7 & & & Mean & 44.1 & 43.7 & \\
\hline
\end{tabular}

*Oryza sativa cvs: Giza 177 (expts 2, 3, 8, 13), Sakha 101 (expts 7, 9), Sakha 102 (expts 1, 14), Sakha 103 (expts 5, 6), Sakha 104 (expts 10,12), Sakha 105 (expt 11). For each experiment, means of the harvest index superscripted by different letters in the same column (for $\mathrm{N}$-fertilization doses) or their values highlighted in bold (for inoculation treatments) are significantly different from the mean of the corresponding uninoculated control at the $95 \%$ confidence level. $* \%$ of grain yield /above ground grain + straw at harvest. 
Differential Performance of Individual and Consortial Endophytes for Enhanced Rice Yield and Agronomic N-Use Efficiency in Open-Fields in the Nile Delta

Agronomic fertilizer N-use efficiency

Data presented in Table 8 indicate a clear inverse interrelationship between the increased doses of $\mathrm{N}$ fertilizer and the agronomic fertilizer $\mathrm{N}$-use efficiency (kg paddy yield/kg fertilizer-N), independently of whether the plants received biofertilization. However, also Figure 4 indicates that biofertilization significantly increased the growth benefit of $\mathrm{N}$ fertilizer application compared to the corresponding non-inoculated counterparts.

Table 8: Effect of rice* inoculation with an individual strain or consortia of Rhizobium leguminosarum bv. trifolii strain E11, Pseudomonas stutzeri strain ERP1 or Nostoc sp. strain ERC4 on the agronomic fertilizer-N use efficiency** at 14 field locations in the Nile delta during the 2009 and 2010 cultivation seasons.

\begin{tabular}{|c|c|c|c|c|c|c|c|c|c|}
\hline \multirow[t]{2}{*}{ Expt } & \multirow{2}{*}{$\begin{array}{l}\text { Applied N } \\
\text { (kg/ha) }\end{array}$} & \multicolumn{2}{|c|}{ Inoculation } & \multirow[b]{2}{*}{ Mean } & \multirow[t]{2}{*}{ Expt } & \multirow{2}{*}{$\begin{array}{c}\text { Applied } \\
\text { N (kg/ha) }\end{array}$} & \multicolumn{2}{|c|}{ Inoculation } & \multirow[t]{2}{*}{ Mean } \\
\hline & & Control & Inoculated & & & & Control & Inoculated & \\
\hline \multirow[t]{4}{*}{1} & 48 & 194.8 & 209.4 & $133.1^{\mathrm{c}}$ & \multirow[t]{4}{*}{8} & 48 & 178.4 & 195.3 & $186.9^{c}$ \\
\hline & 96 & 103.7 & 112.2 & $108.0^{\mathrm{b}}$ & & 96 & 96.4 & 96.2 & $96.3^{\mathrm{b}}$ \\
\hline & 144 & 72.6 & 77.8 & $75.2^{\mathrm{a}}$ & & 144 & 57.9 & 69.3 & $63.6^{a}$ \\
\hline & Mean & 123.7 & 133.1 & & & Mean & 110.9 & 120.3 & \\
\hline \multirow[t]{4}{*}{2} & 48 & 174.0 & 177.5 & $175.8^{c}$ & \multirow[t]{4}{*}{9} & 48 & 168.4 & 203.1 & $185.8^{c}$ \\
\hline & 96 & 95.8 & 98.6 & $97.2^{\mathrm{b}}$ & & 96 & 89.4 & 105.9 & $97.7^{\mathrm{b}}$ \\
\hline & 144 & 67.4 & 67.9 & $67.7^{\mathrm{a}}$ & & 144 & 58.2 & 71.8 & $65.0^{\mathrm{a}}$ \\
\hline & Mean & 112.4 & 114.7 & & & Mean & 105.3 & 126.9 & \\
\hline \multirow[t]{4}{*}{3} & 48 & 99.7 & 103.0 & $101.4^{\mathrm{c}}$ & \multirow[t]{4}{*}{10} & 48 & 181.3 & 192.1 & $186.7^{\mathrm{c}}$ \\
\hline & 96 & 66.7 & 67.7 & $67.2^{\mathrm{b}}$ & & 96 & 91.7 & 97.1 & $94.4^{\mathrm{b}}$ \\
\hline & 144 & 54.9 & 57.3 & $56.1^{\mathrm{a}}$ & & 144 & 61.8 & 65.1 & $63.5^{\mathrm{a}}$ \\
\hline & Mean & 73.8 & 76.0 & & & Mean & 111.6 & 118.1 & \\
\hline \multirow[t]{4}{*}{4} & 48 & 104.7 & 109.4 & $107.1^{\mathrm{c}}$ & \multirow[t]{4}{*}{11} & 48 & 175.5 & 194.1 & $184.8^{\mathrm{c}}$ \\
\hline & 96 & 67.2 & 69.7 & $68.5^{\mathrm{b}}$ & & 96 & 97.2 & 104.4 & $100.8^{\mathrm{b}}$ \\
\hline & 144 & 59.1 & 58.7 & $58.9^{\mathrm{a}}$ & & 144 & 66.0 & 73.8 & $69.9^{\mathrm{a}}$ \\
\hline & Mean & 77.0 & 79.3 & & & Mean & 112.9 & 124.1 & \\
\hline \multirow[t]{4}{*}{5} & 48 & 175.7 & 183.9 & $179.8^{c}$ & \multirow[t]{4}{*}{12} & 48 & 179.2 & 200.5 & $189.9^{c}$ \\
\hline & 96 & 99.7 & 98.7 & $99.2^{\mathrm{b}}$ & & 96 & 96.4 & 106.7 & $101.6^{\mathrm{b}}$ \\
\hline & 144 & 61.3 & 68.4 & $64.9^{\mathrm{a}}$ & & 144 & 67.7 & 75.1 & $71.4^{\mathrm{a}}$ \\
\hline & Mean & 112.2 & 117.0 & & & Mean & 114.4 & 127.4 & \\
\hline \multirow[t]{4}{*}{6} & 48 & 180.2 & 189.0 & $184.6^{c}$ & \multirow[t]{4}{*}{13} & 48 & 99.0 & 117.5 & $108.3^{\mathrm{c}}$ \\
\hline & 96 & 99.5 & 102.2 & $100.9^{b}$ & & 96 & 69.5 & 71.4 & $70.5^{b}$ \\
\hline & 144 & 69.1 & 73.3 & $71.2^{\mathrm{a}}$ & & 144 & 56.8 & 59.6 & $58.2^{\mathrm{a}}$ \\
\hline & Mean & 116.3 & 121.5 & & & Mean & 75.1 & 82.8 & \\
\hline \multirow[t]{4}{*}{7} & 48 & 244.8 & 262.1 & $253.5^{c}$ & \multirow[t]{4}{*}{14} & 48 & 181.3 & 186.3 & $183.8^{\mathrm{c}}$ \\
\hline & 96 & 117.2 & 132.7 & $125.0^{\mathrm{b}}$ & & 96 & 96.4 & 102.9 & $99.7^{\mathrm{b}}$ \\
\hline & 144 & 81.6 & 91.4 & $86.5^{\mathrm{a}}$ & & 144 & 66.0 & 70.9 & $68.5^{\mathrm{a}}$ \\
\hline & Mean & 147.9 & 162.1 & & & Mean & 114.6 & 120.0 & \\
\hline
\end{tabular}

* Oryza sativa cvs: Giza 177 (expts 2, 3, 4, 8, 13), Sakha 101 (expts 7, 9), Sakha 102 (expts 1, 14), Sakha 103 (expts 5, 6), Sakha 104 (expts 10,12), Sakha 105 (expt 11). For each experiment, means of the agronomic fertilizer N-use efficiency** superscripted by different letters in the same column (for $\mathrm{N}$-fertilization doses) or their values highlighted in bold (for inoculation treatments) are significantly different from the mean of the corresponding uninoculated control at the $95 \%$ confidence level. ${ }^{* *}$ Agronomic fertilizer N-use efficiency: kg grain yield/kg fertilizer-N applied. 


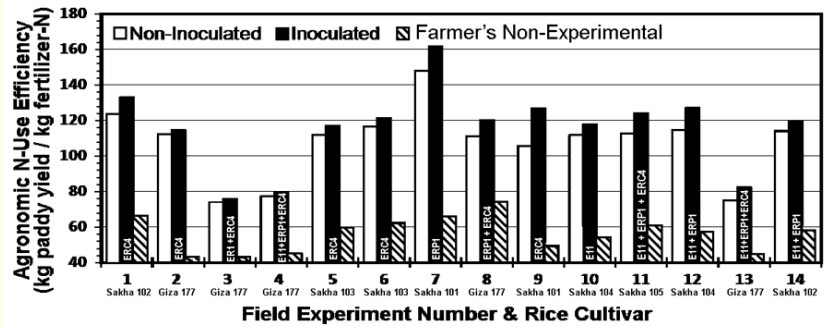

Figure 4: Best agronomic fertilizer-N use efficiency, responding rice cultivar and biofertilizer formulation obtained at 14 field locations with and without inoculation under optimal agronomic conditions vs. farmers' non-experimental treatment.

The mean values of rice agronomic fertilizer N-use efficiency over the 14 experimental field tests with application of the 48, 96 and $144 \mathrm{~kg} \mathrm{~N} /$ ha without inoculation recorded 166.9, 91.9 and $64.0 \mathrm{~kg}$ paddy rice / kg fertilizer-N, respectively, increased by inoculation to $181.6,98.6$ and 91.9 , in the same respective order. The agronomic N-use efficiency of the 6 rice varieties was further compared at the 3 levels of $\mathrm{N}(48,96$, and $144 \mathrm{~kg} \mathrm{~N})$ with and without biofertilizer inoculation (Figure 5). Also, two multivariable cluster analyses (dendrogram of Ward's Increase in Sum of Squares and Multidimensional Scaling scatterplot) indicated that the cvs Sakha 102, Sakha 103, and Sakha 104 clustered with high similarity. The response of this group differed significantly from the response obtained for the cultivars Giza 177 and Sakha 101 cultivars (Figure 6, Figure 7). These multivariate analyses on similarities and differences in the agronomic fertilizer-N use efficiency clearly indicate how these rice cultivars differ in their responses to inoculation and fertilizer- $\mathrm{N}$ treatments.

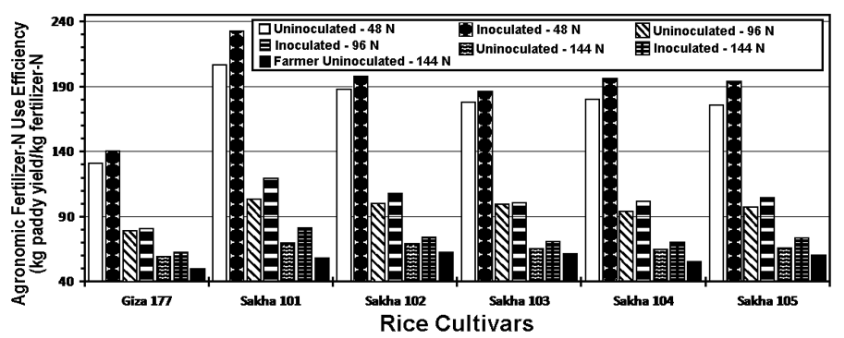

Figure 5: Comparison of means of the best agronomic fertilizer$\mathrm{N}$ use efficiency for 6 rice varieties at 3 fertilizer- $\mathrm{N}$ levels with and without biofertilizer inoculation vs. farmers' non-experimental treatment.

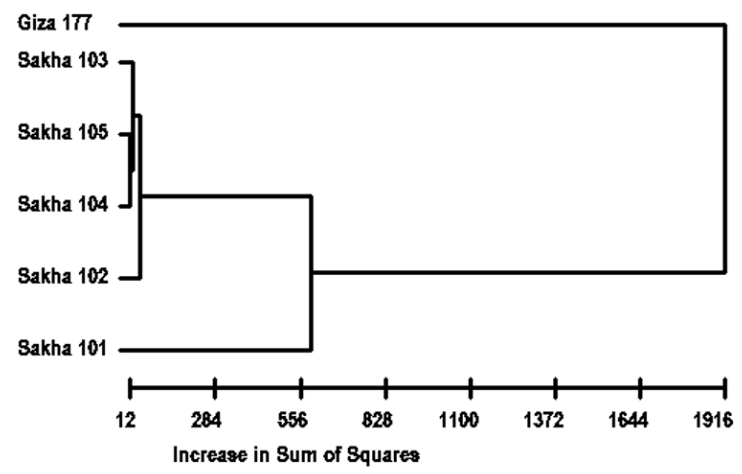

Figure 6: Dendrogram indicating the relatedness in responsiveness of agronomic fertilizer-N use efficiency for 6 rice varieties under conditions of 3 fertilizer-N levels, uninoculated vs. inoculated, and farmer's non-experimental treatment. Values are computed from Ward's increase in sum of squares.

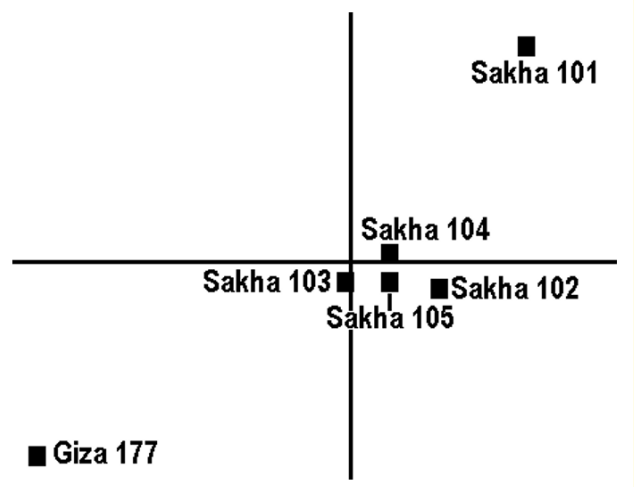

Figure 7: Multidimensional scaling cluster analysis of relatedness in responsiveness of agronomic fertilizer- $\mathrm{N}$ use efficiency for 6 rice varieties under conditions of 3 fertilizer-N levels, uninoculated vs. inoculated, and farmer's nonexperimental treatment.

These results also provide a clear indication of how biofertilization can increase the efficiency in production of paddy rice relative to the amount of $\mathrm{N}$-fertilizer applied. In contrast, the overall mean values of the agronomic fertilizer $\mathrm{N}$-use efficiency obtained by the farmers using their agronomic practices in each of their 14 adjacent fields with application of the recommended dose of $144 \mathrm{~kg} \mathrm{~N} /$ ha ranged from 43.9 to 73.8 with a mean of $56.0 \pm 9.7$ $\mathrm{kg}$ paddy yield/kg fertilizer-N. Thus, a consequence of using the 
farmers' conventional agronomic practices instead of the recommended practices for rice production management [(http://www. fcri-egypt.org/AboutFCRI.htm). (Accessed 20 June 2019)] resulted in more than a $14.3 \%$ loss in the fertilizer N-use efficiency compared to the corresponding values obtained with the recommended agronomic practices followed by the research team using the same quantity of $144 \mathrm{~kg} \mathrm{~N} / \mathrm{ha}$, even without inoculation.

\section{Discussion}

The capacity to fix nitrogen is widely distributed in phyla of bacteria and archaea but has long been considered uncommon in the genus Pseudomonas. [19] developed an oxygen gradient system and a complex medium for isolation of a microaerobically $\mathrm{N}_{2}$-fixing heterotrophic bacterium from the rhizosphere of a "high fixing" Sorghum nutans cultivar. They identified the isolate as a $\mathrm{Nif}^{+}$ phenotype of Pseudomonas stutzeri on the basis of cultural, physiological and biochemical characteristics including DNA/DNA hybridization. $\mathrm{N}_{2}$ fixation by the isolate was demonstrated by assimilation of $\mathrm{N}^{15}$ into cellular protein and presence of one $30 \mathrm{MD}$ plasmid that could be cured with associated loss of N2 fixation capability. This work was later confirmed [20,21]. Five years later, [22] reported the complete genome sequencing of the $\mathrm{N}_{2}$-fixing root-associated Pseudomonas stutzeri (A1501). Its genome contains genes involved in broad utilization of carbon sources, nitrogen fixation, denitrification, degradation of aromatic compounds, biosynthesis of polyhydroxybutyrate, multiple pathways of protection against environmental stress, and other functions that presumably give this bacterial strain an advantage in root colonization and beneficial actions on the growth and performance of the plant hosting it endophytically in its root. Our study adds information on the isolation of an endophytic strain of $P$. stutzeri from within soil-grown surface-sterilized rice roots and its ability to perform as an efficient biofertilizer capable of promoting rice growth in large-scale field inoculation experiments.

Inoculation with soil-based inocula of cyanobacteria has frequently been recommended for enhancement of rice growth and performance. Chronologically, the mechanisms of this enhancement involve antagonism against aquatic macrophytes [23,24], enhancement of biological $\mathrm{N}_{2}$-fixation and paddy yield $[17,25]$, reduction of sulfide injury in flooded rice fields [26], promotion of soil particle aggregation with increased soil organic matter content, permeability, water retention and water holding capacity [27], diminished epidemic injuries by fungi $[28,29]$ and insect pests [30], increase rice protection against the "rosette long-day" disorder [31], increased rice branching and positive turnover effects on subsequent crops that follow rice in crop rotation [28,32-34], contributed available P during the rice panicle initiation stage [34] and alleviation of salt stress in rice fields [35]. Several positive effects of inoculation with cyanobacteria are recorded throughout.
This study describes the performance of a cyanobacterial strain with taxonomic affinity to Nostoc that was isolated from soil-grown surface-sterilized rice roots and used as an efficient growth-promoting biofertilizer individually and in consortia in extensive rice

The Rhizobium leguminosarum bv. trifolii strain E11 (among other strains) was isolated from field grown rice roots, tested gnotobiotically for enhancement of growth of its natural legume host (Trifolium alexandrinum) and rice (Oryza sativa) cultivars. It was an effective and efficient growth promoter of both plants, but different in the mechanisms by which it infects these plants and contributes fixed $\mathrm{N}$ involving root nodulation of the natural legume host, the Trifolium alexandrinum, and by endocolonization of the rice root $[8,9]$. This organism enhances rice growth by production of phytohormones and siderophores, expansion of root architecture associated with higher capabilities of nutrient mining from the growth substrates, and dissolution of inorganic and organic phosphates [9].

None of the three tested organisms was able to completely fulfill the $\mathrm{N}$ demand of the rice crop, so the full potential of paddy production could not be achieved without additions of fertilizer-N. We examined the three biofertilizer strains in consortia inoculation to diminish the need for application of currently recommended quantities of fertilizer- $\mathrm{N}$ use to significantly increase the produced paddy yield from a given field area over that of the corresponding adjacent non-inoculated field area. We examined this hypothesis by evaluating two or the three organisms used simultaneously in rice fields. This translational research study was designed to determine whether an inoculum containing endophytic strains of Nostoc, Pseudomonas or Rhizobium performs better when they are used alone, or when they are consortialized in double or triple strain preparations, and whether the consortia contributed additional support to rice growth and performance, thereby broadening and enhancing applications of the biofertilization technology by one or multi genera to a wider scope. However, the detailed mechanism(s) used by our consortial inoculants that embraces the complicated soil/plant/microbe/environment interactions is not defined in this work.

Our original experimental design for this study was to include a local endophytic strain of Azospirillum isolated from surface-sterilized rice roots using conventional protocols and a proposed medium [11] improved 40 years later [36]. We conducted two annual cycles of isolations of Azospirillum from surface-sterilized field-grown rice roots that yielded pure culture isolates matching the conventional description of the morphology, cultural features and biochemistry of azospirilla. However, their 16S rDNA sequences unexpectedly had the highest sequence similarity to taxa of Pseudomonas species (especially P. stutzeri), not azospirilla! Similar results occurred in both cycles of isolation/identification, leaving 
Differential Performance of Individual and Consortial Endophytes for Enhanced Rice Yield and Agronomic N-Use Efficiency in Open-Fields in the Nile Delta

no doubt of its accuracy and reproducibility. Since Pseudomonas stutzeri is documented as a $\mathrm{N}_{2}$-fixer PGPR isolated in this work from inside surface-sterilized rice and previously from other plant roots [19-22], we decided to explore the growth responses of field grown rice to inoculation with one of those isolates, tested individually and in consortia with the other two endophytic strains isolated also from surface-sterilized rice roots.

When we gnotobiotically tested the potential of the chosen strains to promote growth of four rice cvs, inoculation with the rhizobial strain E11 stimulated growth of their roots and shoots, confirming the results of Yanni., et al. $(1997,2001,2010)[8,9,10]$. Similar growth promotions also occurred with the Pseudomonas stutzeri strain ERP1. However, various quantitative measurements indicated that gnotobiotic rice growth was better when inoculated with these 2 test strains than with the cyanobacterial strain ERC4, either alone or in consortia with them. Under the closed gnotobiotic bioassay system, the cyanobacterium effectively competed with the plant (and possibly with the other inoculant strains) for the limited nutrient contents of the growth substrate. The ERC4 cyanobacterial strain produced a very thick and profuse abundance of green growth in the root zone within 5 - 6 days (Figure 2 in the "Online Resource"), which likely created nutrient starvation stress for the plant that could not be alleviated by the other inoculant strains included in the growth system. However, rice growth in open fields generally does not suffer such consequences of effective nutrient competition when inoculated with cyanobacteria [34,37-39]. The plant there can access other sources of available nutrients including the field soil itself, irrigation water, continuous mineralization of plant residues, small animals and macro and micro system inhabitants, along with contribution of atmospheric $\mathrm{N}_{2}$-fixation by numerous microorganisms. However, $\mathrm{P}$ is an exception as it is consumed by cyanobacteria during the early stages of rice growth and re-liberated during the later stages of panicle initiation and flowering. For that reason, it is necessary during the soil tillage for rice cultivation to apply a dose of phosphate fertilizer in case of limited $P$ availability in rice fields in numerous districts $[23,25,35,40]$, including the Egypt rice fields in the Nile delta [9,34]. An important lesson learned from this study was that the short-term gnotobiotic tube culture is not an optimal design for assessment of rice growth-promotion by cyanobacteria or consortia containing them. In any event, in addition to the published studies mentioned above, an abundance of scientific literature documents the potential benefit derived from using individual strains belonging to the three genera tested here as single-strain biofertilizer inoculants for rice in lab, greenhouse and free open rice fields [3,8,9,10,18,41-55].

Unlike the well-known suppression of symbiotic nitrogen fixation accompanying supplementation with high doses of $\mathrm{N}$-fertilizers to legume fields, the degree of benefits to rice by inoculation with rhizobia (Tables 3 through 8, Figure 3 through 7 and Figure 2 in the "Online Resource") continue to be enhanced rather than suppressed by application of ascending amounts of $\mathrm{N}$-fertilizer within the recommended $\mathrm{N}$ application rate of $144 \mathrm{~kg} \mathrm{~N} / \mathrm{ha}$. This same result occurred in previous rice biofertilization studies assisted with natural abundance $\Delta \mathrm{N}^{15}$ studies on field grown rice plants, acetylene reduction assays of rhizobia-rice gnotobiotic cultures, and assessments of their increased sequestration and efficiency of nutrient acquisition related to an improved root architecture and phytohormone production $[8,9,10,57]$. These studies provided evidence that the growth benefit to rice by this rhizobial biofertilizer strain does not involve biological nitrogen fixation. The high significant increase in rice straw occurring in the field when rice was inoculated with the Nostoc strain ERC4 along with high fertilizer-N application (144 kg/ha) (Table 6) indicates that the significant benefit of this inoculant strain in this case is also not mostly due to biological $\mathrm{N}_{2}$-fixation, confirming previous results on the positive actions of cyanobacteria in rice fields in addition to nitrogen fixation [25].

A major strength of this translational study was the use of relatively large land areas under experimental investigation. The 14 field inoculation experiments included, in each, 96 subplots each of $20 \mathrm{~m}^{2}$ (a total of 1344 subplots having a net field plots area of 2.688 ha conducted on 3.226 ha of open fields). This large area of experimentation enabled better evaluation of the performance of the tested biofertilizers under numerous soil characteristics, irrigation water sources and qualities and efficiencies of drainage systems that exemplified most of the variations in these agronomic categories that occur widely in the Egypt Nile delta. In this study, the three main-plot treatments of $\mathrm{N}$ supplementation did not include ones without added fertilizer- $\mathrm{N}$ nor with $\mathrm{N}$-fertilization doses greater than the recommended quantity of $144 \mathrm{~kg} \mathrm{~N} /$ ha assigned for the tested rice cvs. This design is based on prior work showing that the performance of rhizobial biofertilizers performed much better when combined with low or intermediate doses of fertili- 
zer-N $[8,9,10,56]$. Also, the cooperated farmers would not sacrifice their farmland for sub-treatments lacking application of chemical $\mathrm{N}$-fertilizers, knowing for certain that this would be catastrophic to their production economy. Our policy in the field experimentation followed the recommended agronomic practices given to the rice farmers (http://www.fcri-egypt.org/AboutFCRI.htm. Accessed in 20 June 2019), and additionally, assist them by contributing modern, economic farm management practices including environmental friendly biofertilization technologies, targeting production of significant higher yield and fertilizer $\mathrm{N}$-use efficiency, i.e., to collect higher yield from a given field area using the recommended rate of fertilizer-N; not more and better to be less!

The use of inoculants containing rhizobia differs from "non-rhizobial" ones like preparations of N-fixing cyanobacteria, AzospiriIlum, Pseudomonas, Azotobacter, etc., in two major ways. First, the appropriate rhizobia can benefit both the legume and the cereal hosts (as in the rice-berseem clover rotation in the Nile delta), whereas these other PGPR typically only benefit a cereal or a legume. In Egypt, around $67 \%$ of rice cultivation is done in rotation with berseem clover, and that regimen can help to maintain the populations of clover rhizobia involved in the beneficial plant-microbe interactions with both crop hosts. Second, rhizobial inoculants benefit rice at all stages of its development, beginning at the seedling stage and extending throughout the crop growth cycle up to grain maturity $[8,9,10,18,58-60]$, whereas other biofertilizer inoculants only benefit rice during the short growth period of the tillering stage $\left(15^{\text {th }}\right.$ to $40^{\text {th }}$ days post transplantation). The maximum $\mathrm{N}$-limitation stress normally occurs during that period, and therefore an external source of $\mathrm{N}$ must be supplied [62].

This study documenting also the beneficial field growth responses of rice to biofertilization with rice endophytic Pseudomonas and Nostoc strains (Tables 3 - 8 in this context) coincide with similar results presented by other investigators using different agronomic practices, agrochemicals, variation in soil characteristics, rice cvs, under different agro-climatic conditions and ecosystems. They documented the effects of inoculation with Pseudomonas [22,53,63$65]$.

The yield data indicate statistically significant first order interactions between $\mathrm{N}$-fertilization and inoculation, i.e. the magnitude of benefit from the added $\mathrm{N}$ fertilizer [expressed as the agronomic $\mathrm{N}$-use efficiency (kg paddy yield/kg fertilizer-N)] concomitantly decreased with application of every higher N-fertilizer quantity. However, the contribution of biofertilization to grain yield showed significant increases with application of the three ascending doses of $\mathrm{N}$-fertilizer. In addition, the yield increases obtained by the research team were significantly higher than what was obtained in the adjacent farmer's yield, even without inoculation (Table 5). This is likely due to implementation of standard recommended agronomic practices containing optimal field stand densities, balanced NPK fertilization treatments, integrated pest control management, proper water supplementation, efficient drainage systems and others that were followed by the researchers compared to the conventional practices used by the farmers. Unfortunately, most of these proper field management operations not followed by most of the rice farmers in our experimentation districts!

Some of the rice straw produced in Egypt is used as filler fodder for domestic farm animals, in manufacture of byproducts including clay/straw building bricks in small margin villages, processed synthetic wood and packaging filler material. Statistically significant increases in straw yield resulting from inoculation (Table 6) is then of importance regarding these aspects of the rice production economy. The increase in straw production found in this work is consistent with earlier studies showing that inoculation with certain endophytic strains of rhizobia significantly increased rice tillering, leaf area plant height with enhanced photosynthetic capacity in open field (8) and in greenhouse experiments [43, 44, 46, 65]. Interestingly, this study found that straw biomass production was more responsive to $\mathrm{N}$-fertilization than to biofertilization. In contrast, biofertilization improved rice grain production more than did for straw biomass production. This important differential result is a desired positive benefit of biofertilization. It inevitably leads to a probability that the beneficial relationship between rice and the tested microorganisms intensifies the plant's growth physiology in ways that increase its reproductive grain production more so than vegetative straw biomass production.

The results here suggest that the growth characters formulating the ratio between the amounts of rice paddy grain produced in proportion to the total harvested biomass (the harvest index) (Table 7 ) is not greatly affected by the biofertilization practice. Interestingly, the figures fluctuated in a narrow range towards both the main treatments of $\mathrm{N}$-fertilization and the sub-treatments of biofertilization, similarly in all the 14 field experiments, with relatively 
non-significant higher figures with inoculation. Nevertheless, it is well documented that the harvest index sharply declines by excessive application of $\mathrm{N}$-fertilizer over the recommended amounts [8]. The results also indicate that the combination of inoculation and $\mathrm{N}$-fertilization at the recommended dose worked together synergistically in securing the plant demand for $\mathrm{N}$ without decreasing the harvest index values. This result is consistent with our previous studies $[8,9,60]$ showing that rhizobial inoculation along with $\mathrm{N}$-fertilization positively contributed to rice vegetative growth and grain yield in parallel, not in conflict with one another.

The data in Table 8 indicate significant first order interactions between $\mathrm{N}$-fertilization and inoculation, showing that the magnitude of benefit from the added $\mathrm{N}$ fertilizer [expressed as the agronomic $\mathrm{N}$-use efficiency] decreased with application of higher $\mathrm{N}$-fertilizer doses. Biofertilization benefitted paddy grain production by counter-balancing that trade off in reduced agronomic $\mathrm{N}$-use efficiency with increasing fertilizer- $\mathrm{N}$ application doses. This response relationship provides the desired result that inoculation with individual strains or consortia strains formulations can reduce the need for additional fertilizer- $\mathrm{N}$ application to achieve higher grain yield from a given field area. This finding found here consistently confirms other documented results [2]. Assuming that the farmers used only the recommended fertilizer-N rate of $144 \mathrm{~kg} \mathrm{~N} /$ ha in their adjacent field areas, they obtained a mean of $56.0 \mathrm{~kg}$ paddy yield/kg fertilizer-N comparing to 63.6 and 71.3 mean values recorded for the non-inoculated and inoculated experimental field plots, using the same fertilizer- $\mathrm{N}$ quantity, respectively (Table 5). This latter value indicates that the biofertilization process increased the agronomic fertilizer N-use efficiency by $27.3 \%$ above the mean of $\mathrm{N}$-use efficiencies obtained in the farmers' adjacent field areas using the same rice cvs. The research team obtained a mean of $13.6 \%$ further increase in the N-use efficiency just by critical application of the recommended $\mathrm{N}$ and proper field management practices for rice production even without biofertilization.

\section{Summary and Conclusions}

Underutilization of the ecofriendly biofertilization technology in low input farming systems is mostly related to a catastrophic lack of integration among uninformed farmers, plant breeders, agronomists, ecologists, economists, extension specialists, public health authorities and policy makers.

For eco-biosafety, locally isolated/identified and tested rice root endophytic strains of Nostoc, Rhizobium and Pseudomonas were constituted in individual or consortial biofertilizer preparations that significantly enhanced rice growth, paddy yield and the agronomic fertilizer $\mathrm{N}$-use efficiency in large-scaled, real-world agricultural field conditions in an environmental friendly way that significantly reduced the need for excessive $\mathrm{N}$-fertilizer applications to obtain higher paddy yields from a given land area.

Best paddy yields and agronomic fertilizer N-use efficiencies were achieved by using single strain, double strain consortia or triple strain consortia in 7, 4 and 3 out of the 14 experimental fields, respectively.

Assuming that this technology is adopted into proper field applications by rice producers, our results predict significant increases in rice yield over that which can be obtained using the full recommended dose of chemical fertilizer $\mathrm{N}$ without inoculation, even if the field management practices were critically followed!

Adoption of the biofertilization by locally isolated ecofriendly growth-promoting rhizobacteria can, additionally, diminish many catastrophic environmental pollution and health risks that accompany excessive use of chemical fertilizers with counterbalancing of land and water requirements and the need for additional agrochemicals.

The study shows how deployment of well-selected safe and environmental friendly biofertilizer(s) can become an integral component of sustainable nutrient management for economic rice production under real-world agricultural conditions.

\section{Acknowledgments}

We thank the numerous rice farmers in the 14 field locations listed in Table 1 and the field experimentation experts of the Agricultural Research Center, Egypt for their cooperation and assistance during this study. This work was supported by the US-Egypt Science and Technology Joint Fund project [ID CODE: BI010-001-011]. 


\section{Conflict of Interest}

The authors declare that this translational research work was conducted in the absence of any commercial or financial relationships that could be construed as a potential conflict of interest. We confirm that no part of this manuscript is under consideration by any other journal and the authors have no conflict of interest. All the authors have consented to the submission of this manuscript.

\section{Data availability}

All data generated or analyzed during this study are included in this published article and its online supplementary information files (Click Here to View).

\section{Bibliography}

1. Javier V., et al. "Selection of mixed inoculants exhibiting growth-promoting activity in rice plants from undefined consortia obtained by continuous enrichment". Plant and Soil 375.1-2 (2014): 215-227.

2. Jha M., et al. "Microbial consortium for sustainable rice production". Agroecology and Sustainable Food Systems 37.3 (2013): 340-362.

3. Manjunath M., et al. "Developing PGPR consortia using novel genera Providencia and Alcaligenes along with cyanobacteria for wheat". Archives of Agronomy and Soil Science 57.8 (2011): 873-887.

4. Prasanna R., et al. "Evaluating the establishment and agronomic proficiency of cyanobacterial consortia as organic options in wheat-rice cropping sequence". Experimental Agriculture 49.3 (2013): 416-434.

5. Raia P., et al. "Impact of bio inoculants consortium on rice root exudates, biological nitrogen fixation and plant growth". Journal of Biological Sciences 6.5 (2006): 815-823.

6. Shahzad S., et al. "Comparative effectiveness of different carriers to improve the efficiency of bacterial consortium for enhancing wheat production under salt affected field conditions". Pakistan Journal of Botany 49.4 (2017): 1523-1530.
7. Vanegas J., et al. "Selection of mixed inoculants exhibiting growth-promoting activity in rice plants from undefined consortia obtained by continuous enrichment". Plant Soil 375 (2014): 215-227.

8. Yanni YG., et al. "Natural endophytic association between Rhizobium leguminosarum bv. trifolii and rice and assessment of its potential to promote rice growth". Plant and Soil 194.1-2 (1997): 99-114.

9. Yanni YG., et al. "The beneficial plant growth-promoting association of Rhizobium leguminosarum bv. trifolii with rice roots". Australian journal of plant physiology 28.9 (2001): 845-870.

10. Yanni YG., et al. "Enhancement of rice production using endophytic strains of Rhizobium leguminosarum bv. trifolii in extensive field inoculation trials within the Egypt Nile delta". Plant and Soil 336,1-2 (2010): 129-142.

11. Dobereiner J., et al. "Associative symbioses in tropical grasses: characterization of microorganisms and dinitrogen-fixing sites". In: Newton, WE, Nyman CJ (eds) Proceedings of the first international symposium on nitrogen fixation, 2ed edn. Pullman WA, Washington State University Press (1976):518-538.

12. El-Nawawy AS., et al. "Studies on the ability of some bluegreen algae to fix atmospheric nitrogen and their effect on growth and yield of paddy". Agricultural research review, Ministry of Agriculture Cairo 36 (1958): 308-320.

13. Yanni Y., et al. "Screening of cyanobacteria isolated from soil, rice fields and water resources of the Nile delta for production of cyanotoxins". In: Reguera B, Blanco J, Ferndndez ML, Wyatt $\mathrm{T}$ (eds) Harmful algae. Xunta de Galicia and Intergovernmental Oceanographic Commission of UNESCO (1998).

14. Dazzo FB., "Leguminous root nodules", in: Burns R, Slater J (eds), Experimental microbial ecology. Blackwell Scientific Press, Cambridge (1982): 431-446.

15. Dazzo FB., et al. "Use of CMEIAS image analysis software to accurately compute attributes of cell size, morphology, spatial aggregation and color segmentation that signify in situ ecophysiological adaptations in microbial biofilm communities". Computation 3 (2015): 72-98. 
16. Dazzo FB., et al. "CMEIAS v4.0: Advanced computational tools of bioimage informatics software designed to strengthen microscopy based approaches for understanding microbial ecology". Presented at the All Scientists Meeting of the Michigan State University, Kellogg Biological Station Long-Term Ecological Research program (2017).

17. Venkataraman GS. “Algalization”. Phykos 5 (1966): 164-174.

18. Yanni YG., et al. "Assessment of the natural endophytic association between Rhizobium and wheat and its ability to increase wheat production in the Nile delta". Plant and Soil 407.1-2 (2016): 367-383.

19. Krotzky A., et al. "Nitrogen fixation in Pseudomonas stutzeri". Archives of Microbiology 147.1 (1987): 48-57.

20. Desnoues N., et al. "Nitrogen fixation genetics and regulation in a Pseudomonas stutzeri strain associated with rice". Microbiology 149.8 (2003): 2251-2262.

21. Nicole D., et al. "Nitrogen fixation genetics and regulation in a Pseudomonas stutzeri strain associated with rice". Microbiology 149 (2003): 2251-2262.

22. Yan Y., et al. "Nitrogen fixation island and rhizosphere competence traits in the genome of root-associated Pseudomonas stutzeri A1501". Proceedings of the National Academy of Sciences of the United States of America 105.21 (2008): 75647569.

23. Subrahmanyan R., "Fertility build-up of rice field soils by bluegreen algae". Proceedings of the Indian Academy of Sciences Section B 62 (1965): 252-277.

24. Yanni YG., et al. "Response of transplanted rice to algalization under different treatments of herbicides". Proceedings of the Second Conference of the Agricultural Development Research, Ain-Shams University 2 (1988): 216-226.

25. Roger PA., et al. "Blue-green Algae and Rice". International Rice Research Institute, Los Banos, Philippines.
26. Jack V., et al. "Diminution des fonts de semis dues 'a la sulfatore' duction, par un pre'traitement des grains de riz avec des cyanophyc'ees". Cabiers ORSTOM Serie Biologie 12 (1977): 101-107.

27. Roychoudhury P., et al. "Effect of algal inoculation on soil aggregation in rice soils". Phytos 19 (1980): 224-227.

28. Yanni YG., et al. "Contributions of algalization to rice growth yield, $\mathrm{N}$ attributes and incidence of infestation with the blast fungus Pyricularia oryzae under different fungicidal treatments". World Journal of Microbiology and Biotechnology 6.4 (1990): 371-376.

29. Yanni YG., et al. "Rice performance and natural infection with blast (Pyricularia oryzae Cav.) under different algalization techniques and rates of fertilizer nitrogen". World Journal of Microbiology and Biotechnology 7.1 (1991): 43-47.

30. Yanni YG., et al. "Role of algalization in rice growth, yield and incidence of infestation with the stem borer Chilo Agamemnon Bles. and the leaf miner Hydrellia prosternalis Deeming in the Nile Delta". World Journal of Microbiology and Biotechnology 6.4 (1990): 383-389.

31. Yanni YG. "Protection of rice against rosette long-day disorder by inoculation with Aulosira fertilissima vs. treatment with gibberellic acid". World Journal of Microbiology and Biotechnology 7.3 (1991): 436-438.

32. Yanni YG. "Efficiency of rice fertilization schedules including cyanobacteria under soil application of phosphate and molybdate". World Journal of Microbiology and Biotechnology 7.3 (1991): 415-418.

33. Yanni YG. "Potential of indigenous cyanobacteria to contribute to rice performance under different schedules of nitrogen application". World Journal of Microbiology and Biotechnology 7.1 (1991): 48-52.

34. Yanni YG., et al. "Assessing phosphorus fertilization of rice in the Nile Delta involving nitrogen and cyanobacteria". Soil Biology and Biochemistry 25.2 (1993): 289-293. 
35. Arora M., et al. "Effect of cyanobacterial exopolysaccharides on salt stress alleviation and seed germination". Journal of Environmental Biology 31.5 (2010): 701-704.

36. Pereg L., et al. "Assessment of affinity and specificity of Azospirillum for plants". Plant and Soil 399.1-2 (2016): 389-414.

37. Yanni YG. "Fertilizer responses of rice to nitrogen and cyanobacteria in the presence of insecticides". Soil Biology and Biochemistry 24.11 (1992): 1085-1088.

38. Yanni YG. "The effect of cyanobacteria and azolla on the performance of rice under different levels of fertilizer nitrogen". World Journal of Microbiology and Biotechnology 8.2 (1992): 132-136.

39. Yanni YG., et al. "Population density and sequential distribution of dinitrogen fixing cyanobacteria in rice fields with application of herbicides". The 1999 Brighton Conference-Weeds (1999): 217-224.

40. Mishra U., et al. "Cyanobacteria: A potential biofertilizer for rice". Resonance 9.6 (2004): 6-10.

41. Anandaraj B., et al. "Studies on influence of bioinoculants (Pseudomonas fluorescens, Rhizobium sp., Bacillus megaterium) in Green gram". Journal of Food Biosciences and Technology 1 (2010): 95-99.

42. Bhattachariee RB., et al. "Use of nitrogen-fixing bacteria as biofertilizer for non-legumes: prospects and challenges". Applied Microbiology and Biotechnology 80.2 (2008): 199-209.

43. Biswas JC., et al. "Rhizobia inoculation improves nutrient uptake and growth of lowland rice". Soil Science Society of America Journal 64.5 (2000): 1644-1650.

44. Biswas JC., et al. "Rhizobial inoculation influences seedling vigor and yield of rice”. Agronomy Journal 92.5 (2000): 880886.

45. Chaintreuil C., et al. "Photosynthetic bradyrhizobia are natural endophytes of the African wild rice Oryza breviligulata". Applied and Environmental Microbiology 66.12 (2000): 54375447.
46. Chi F., et al. "Ascending migration of endophytic rhizobia, from roots to leaves, inside rice plants and assessment of benefits to rice growth physiology". Applied and Environmental Microbiology 71.11 (2005): 7271-7278.

47. Cong PT., et al. "Inoculant plant growth-promoting microorganisms enhance utilization of urea-N and grain yield of paddy rice in southern Vietnam". European Journal of Soil Biology 45.1 (2009): 52-61.

48. Egamberdiev D., et al. "Co-inoculation of Pseudomonas spp. with Rhizobium improves growth and symbiotic performance of fodder galega (Galega orientalis Lam.)". European Journal of Soil Biology 46.3-4 (2010): 269-272.

49. Glick BR. "The enhancement of plant growth by free-living bacteria". Canadian Journal of Microbiology 41.2 (1995): 109117.

50. Hartmann A., et al. "Plant responses to bacterial quorum sensing molecules". Front Plant Science 6 (2015): 643.

51. Hussain A., et al. "Effect of IAA on in vitro growth and colonization of Nostoc in plant roots. Frontiers in Plant Science". Plant-Microbe Interaction 6 (2015): 46.

52. Jensen ES., et al. "How can increase use of biological N2-fixation in agriculture benefit the environment?". Plant and Soil 252.1 (2003): 177-186.

53. Karthikeyan N., et al. "Evaluating the potential of plant growthpromoting cyanobacteria as inoculants for wheat". European Journal of Soil Biology 43.1 (2007): 23-30.

54. Ladha JK., et al. "Nitrogen fixation in rice systems: state of knowledge and future prospects". Plant and Soil 252.1 (2003): 151-167.

55. Rosenblueth M., et al. "Nitrogen fixation in cereals". Frontiers in Microbiology (2018).

56. Yanni YG., et al. "Status of the biofertilization technology and biosafety of biofertilizers in Egypt". In: Pati B, Mandal SM (eds) Recent trends in biofertilizers. International Publishers, New Delhi India (2016): 19-36. 
57. Yanni YG., et al. "Natural beneficial endophytic association of Rhizobium leguminosarum bv. trifolii and rice roots and its relevance to sustainable agriculture". In: Dakora FD (ed) Biological nitrogen fixation: towards poverty alleviation through sustainable agriculture. African Association for Biological Nitrogen Fixation (1998): 284-285.

58. Dazzo FB., et al. "The natural Rhizobium-cereal crop association as an example of plant-bacteria interaction". In: Uphoff, N. et al. (eds) Biological approaches to sustainable soil systems. Taylor and Francis, Boca Raton (2006): 109-127.

59. Dazzo FB., et al. "The natural beneficial association between Rhizobium leguminosarum bv. trifolii and rice and its exploitation in sustainable agriculture". In: Proceedings of the International Symposium on Nitrogen-Fixation and Crop Production, Cairo, Egypt (1999): 135-140.

60. Dazzo FB., et al. "Progress in multinational collaborative studies on the beneficial association between Rhizobium leguminosarum bv. trifolii and rice". In: Ladha JK, Reddy PM (eds) The quest for nitrogen fixation in rice. IRRI press, Los Banos, Philippines (2000): 167-189.

61. Prayitno J., et al. "Interactions of rice seedlings with bacteria isolated from rice roots". Australian journal of plant physiology 26.6 (1999): 521-535.

62. Yanni YG., et al. "Towards integrated biofertilization management with free living and associative dinitrogen fixers for enhancing rice performance in the Nile Delta". Symbiosis 27.3 (1999): 319-331.

63. Choudhary DK., et al. "Insights of the fluorescent Pseudomonads in plant growth regulation". Current science 97.2 (2009): 170-179.
64. Choudhury ATMA., et al. "Prospects and potentials for systems of biological nitrogen fixation in sustainable rice production". Biology and Fertility of Soils 39.4 (2004): 219-227.

65. Gholami A., et al. "The effect of plant growth-promoting rhizobacteria (PGPR) on germination, seedling growth and yield of maize". World Academy of Science, Engineering and Technology 49.1 (2009): 19-24.

\section{Volume 2 Issue 8 August 2019 \\ (C) All rights are reserved by Youssef G Yanni., et al.}

